\title{
Hydrogen and Deuterium Loss from the Terrestrial Atmosphere: A Quantitative Assessment of Nonthermal Escape Fluxes
}

\author{
Yuk L. Yung, Jun-Shan Wen, ${ }^{1}$ Julianne I. Moses, Bridget M. LaNDRY, \\ AND MARK ALLEN ${ }^{2}$
}

Division of Geological and Planetary Scrences, California Instrtute of Technology, Pasadena

KUANG-JUNG HSU ${ }^{3}$

Earth and Space Science Division, Jet Propulsion Labonatory, California Institute of Technology, Pasadena

\begin{abstract}
A comprebensive one-dimensional photochemical model extending from the middle atmosphere $(50 \mathrm{~km})$ to the exobase $(432 \mathrm{~km})$ has been used to study the escape of hydrogen and deuterium from the Earth's atmosphere. The model incorporates recent advances in chemical kinetics as well as atmospheric observations by satellites, especially the Atmosphere Explorer $C$ satellite. The results suggest: (1) the escape fluxes of both $\mathrm{H}$ and $\mathrm{D}$ are limited by the upward transport of total hydrogen and total deuterium at the homopause (this result is known as Hunten's limiting flux theorem); (2) about one fourth of total hydrogen escape is thermal, the rest being nonthermal (3) escape of $D$ is nonthermal; and (4) charge exchange and polar wind are important mechanisms for the nonthermal escape of $H$ and $D$, but other nonthermal mechanisms may be required. The efficiency to escape from the terrestrial atmosphere for $D$ is $\mathbf{0 . 7 4}$ of the efficiency for $H$. If the difference between the $\mathrm{D} / \mathrm{H}$ ratio measured in deep-sea tholeiite glass and that of standard sea water, $\delta D=-77 \%$, were caused by the escape of $\mathrm{H}$ and $\mathrm{D}$, we estimate that as much water as the equivalent of $36 \%$ of the present ocean might have been lost in the past.
\end{abstract}

\section{INTRODUCTION}

The escape of hydrogen from the terrestrial atmosphere is an interesting and important problem because of its obvious relationship to the stability and evolution of the atmosphere [Chamberlain, 1963; Walker, 1977], its possible connection with the rise of oxygen in the atmosphere [Berkner and Marshall, 1965; Kasting, 1979], and its role in comparative planetology [Pollack and Yung, 1980]. The problem has been quantitatively investigated in several definitive papers by Hunten and Strobel [1974] and Liu and Donahue [1974 a,b,c]. The literature on the subject, along with comparisons with escape of hydrogen from the atmospheres of other planets, is reviewed by Hunten and Donahue [1976] and Hunten [1982].

The current research is motivated by three reasons. First, we now have a much improved data set of basic chemical kinetics and photodissociation cross sections. Second, there has been a tremendous advance in our understanding of the chemistry and transport processes in the middle atmosphere [World Meteorological Organization (WMO), 1985; Allen et al., 1981, 1984]. Third, the $\mathrm{D} / \mathrm{H}$ ratio in the thermosphere has recently been deduced from a simultaneous measurement of $\mathrm{D}^{+}$and $\mathrm{H}^{+}$by the mass spectrometer on Atmo-

\footnotetext{
${ }^{1}$ Now at Department of Chemistry, University of California, San Diego, La Jolla.

${ }^{2}$ Also at Earth and Space Sciences Division, Jet Propulsion Laboratory, California Institute of Technology, Pasadena, California.

${ }^{3}$ Now at Department of Atmospheric Sciences, National Taiwan University, Taipei, Taiwan, Republic of China.

Copyright 1989 by the American Geophysical Union.

Paper number 89JD00307.

0148-0227/89/89JD-00307\$05.00
}

sphere Explorer C satellite [Breig et al., 1987]. This ratio, $8.4 \times 10^{-4}$ at the exobase, is about 5 times its value at sea level, $1.56 \times 10^{-4}$ [Craig, 1961]. The purpose of this paper is to update and revise the published models of hydrogen escape and to extend the model to include the study of deuterium species. In addition to its intrinsic interest, the work should provide a valuable standard against which calculations of deuterium fractionation on the early Earth and other terrestrial planets can be compared.

Three mechanisms have been shown to be important for the escape of hydrogen from the terrestrial atmosphere: thermal or Jean's escape [Chamberlain, 1963], nonthermal escape, which includes charge exchange [Cole, 1966; Tinsley, 1973], and polar wind [Banks and Holzer, 1969]. In addition, it is now known [Hunten, 1973a, b; Hunten and Strobel, 1974; Liu and Donahue, 1974a, $b, c]$ that the total escape flux of hydrogen is controlled by its source in the lower atmosphere and upward transport through the homopause. A simple theorem, known as Hunten's limiting flux theorem (see section on Thermal Escape), states that the maximum escape flux $\left(\phi_{\ell}\right)$ is given by

$$
\phi_{\ell} \approx \frac{b_{i}}{H_{a}} f_{\imath}
$$

where $b_{i}$ is a binary collision parameter for molecular diffusion, $H_{a}$ is the mean scale height of the atmosphere, and $f_{i}$ is the mixing ratio of total hydrogen (deuterium) at the homopause. From previous work we know that the limiting flux is attained by hydrogen. In this work we shall show that the limiting flux is also attained by deuterium.

The strategy of this paper is as follows. We create the most complete one-dimensional photochemical model to date for hydrogen and deuterium species in the middle atmosphere and the thermosphere. The model provides a re- 
liable estimate of the upward fluxes of total hydrogen and total deuterium through the homopause. We can determine the effective escape velocities by requiring the model to reproduce the observed number densities of $H$ and $D$ at the exobase. As will be shown later, the velocities, $v_{\mathrm{H}}$ and $v_{\mathrm{D}}$, derived from this study greatly exceed those given by the thermal effusion velocities and can provide a quantitative estimate of the nonthermal components of the escape fluxes. Having determined the nonthermal fluxes, we proceed to make a more detailed investigation of the charge exchange and the polar wind mechanism for escape. The results suggest that, within a factor of 2 , we can justify the derived values of nonthermal fluxes. The implications of our model for atmospheric evolution are briefly discussed.

\section{PhOTOCHEMISTRY}

Although the ultimate source of hydrogen-containing species in the upper atmosphere is water in the ocean and methane produced by the biosphere, a chemical model encompassing the middle atmosphere and the thermosphere, from 50 to $432 \mathrm{~km}$, is adequate for investigating the problem of hydrogen escape. The bulk of hydrogen in the middle atmosphere resides in the parent molecules $\mathrm{H}_{2} \mathrm{O}$ and $\mathrm{CH}_{4}$ which have been accurately measured [Farmer et al., 1987]. Since above $50 \mathrm{~km}$ the abundance of $\mathrm{H}_{2} \mathrm{O}$ is much higher than that of $\mathrm{CH}_{4}$, we shall assume for simplicity that the destruction of $\mathrm{CH}_{4}$ always results in the production of $\mathrm{H}_{2} \mathrm{O}$, thereby avoiding a detailed investigation of $\mathrm{CH}_{4}$ photochemistry in the model.

A detailed discussion of the chemistry of the hydrogencontaining radical species $\left(\mathrm{H}, \mathrm{OH}\right.$, and $\left.\mathrm{HO}_{2}\right)$ and the more stable hydrogen-oxygen species $\left(\mathrm{H}_{2}, \mathrm{H}_{2} \mathrm{O}\right.$, and $\left.\mathrm{H}_{2} \mathrm{O}_{2}\right)$ is presented by Allen et al. [1984]. We shall summarize here the important reaction pathways controlling the conversion of $\mathrm{H}_{2} \mathrm{O}$ into $\mathrm{H}_{2}$ and $\mathrm{H}$. These reactions are illustrated in Figure 1 . The reader is referred to Table $1 a$ for a complete listing of the model reaction set.

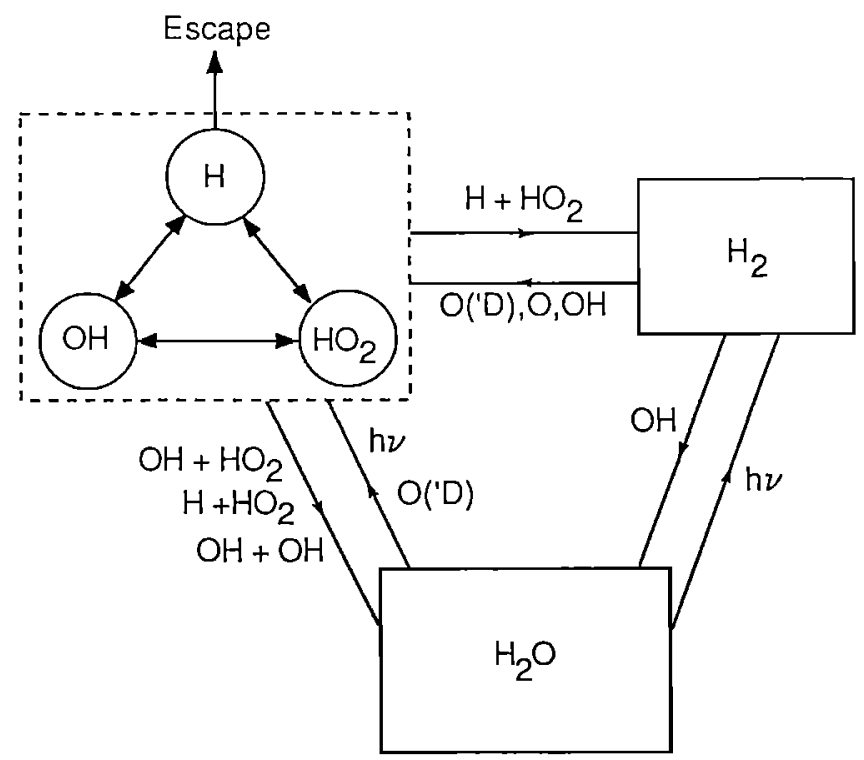

Fig. 1. Important reactions for the conversion of $\mathrm{H}_{2} \mathrm{O}$ to $\mathrm{H}$ and $\mathrm{H}_{2}$. The hydrogen-containing radical species (enclosed in the dashed-line box) interconvert rapidly below the mesosphere, as summarized schematically by the dotted arrows. Reactions between these radical species can result in forming $\mathrm{H}_{2}$ or reforming $\mathrm{H}_{2} \mathrm{O}$.
The first step in the escape of hydrogen is the decomposition of mesospheric $\mathrm{H}_{2} \mathrm{O}$ into $\mathrm{H}$ and $\mathrm{OH}$ or $\mathrm{H}_{2}$ via photolysis or reaction with $O\left({ }^{1} \mathrm{D}\right)$, the latter being derived from $\mathrm{O}_{3}$ photolysis. The hydrogen-containing radicals formed rapidly react with each other to revert back to $\mathrm{H}_{2} \mathrm{O}$, primarily by the $\mathrm{OH}+\mathrm{HO}_{2}$ (reaction (R24), where $\mathrm{Rn}$ is the reaction number in Tables $1 a, 1 b$, and $1 c$ ) channel. In the lower mesosphere, $\mathrm{OH}+\mathrm{OH}$ (R20) also contributes to reforming $\mathrm{H}_{2} \mathrm{O}$, while in the upper mesosphere $\mathrm{H}+\mathrm{HO}_{2}$ (R19c) becomes important.

The $\mathrm{H}_{2} \mathrm{O}$ photolysis channel directly leading to $\mathrm{H}_{2}$ formation (R3b) is $10 \%$ of the total $\mathrm{H}_{2} \mathrm{O}$ decomposition at the mesopause, decreasing in importance with decreasing altitude. The $\mathrm{H}+\mathrm{HO}_{2}$ channel leading to $\mathrm{H}_{2}$ (R19b) can be of equal or greater importance in the mesosphere, depending on altitude. Since $\mathrm{H}_{2}$ is fairly inert chemically, it acts as a carrier of elemental hydrogen to the upper atmosphere.

Above the mesopause, $\mathrm{H}$ is the predominant hydrogencontaining radical and is chemically long-lived relative to upward transport timescales. The decomposition of $\mathrm{H}_{2} \mathrm{O}$ is then an effective source of the $H$ that will diffuse to the exobase and escape from the atmosphere. In this altitude range, $\mathrm{H}_{2}$ is ultimately converted fully into $\mathrm{H}$ by reactions with $\mathrm{OH}(\mathrm{R} 23), \mathrm{O}\left({ }^{1} \mathrm{D}\right)$ (R14), and $\mathrm{O}(\mathrm{R} 5)$.

The important chemical and physical processes governing the escape of deuterium from the Earth's atmosphere are similar to those discussed above for hydrogen. (See Table $1 b$ for a complete listing of reactions related to deuterium chemistry.) The primary reservoirs of $D$ in the middle atmosphere are $\mathrm{HDO}$ and $\mathrm{CH}_{3} \mathrm{D}$. Again, we shall make the simplifying assumption that the destruction of $\mathrm{CH}_{3} \mathrm{D}$ leads to the production of HDO, thus avoiding a detailed investigation of the photochemistry of $\mathrm{CH}_{3} \mathrm{D}$.

The chemical pathways for converting HDO into HD in the mesosphere are analogous to the processes forming $\mathrm{H}_{2}$. Photolysis of HDO can result in D (reaction (R28b) or (R28d)) or OD (R28a). D can be derived from OD via reaction with atomic $\mathrm{O}$ (R35). Rapid recombination with $\mathrm{O}_{2}$ to form $\mathrm{DO}_{2}(\mathrm{R} 41)$ and subsequent reaction with $\mathrm{H}$ (R44b) leads to $\mathrm{HD}$. Also the reaction of $\mathrm{D}$ with $\mathrm{HO}_{2}(\mathrm{R} 43 \mathrm{~b})$ is important for producing $\mathrm{HD}$.

The molecule HD acts as a carrier of deuterium to the upper thermosphere, where it is decomposed by reaction with atomic $\mathrm{O}, \mathrm{O}\left({ }^{1} \mathrm{D}\right)$, and $\mathrm{OH}$ to form $\mathrm{D}$ or OD. Again, OD can be converted to D by (R35). However, at the low densities of the upper thermosphere, three-body recombination is quite slow; the $\mathrm{D}$ produced is relatively inert and can diffuse up to the exobase.

Since much of the chemistry of deuterium species is similar to that for hydrogen, it will not be discussed in detail here. The reader is referred to a paper on hydrogen and deuterium escape from the Martian atmosphere by Yung et al., [1988].

\section{Photochemical Model}

The one-dimensional photochemical model is based on the model of Allen et al. [1981, 1984] for the mesosphere and the lower thermosphere, extended to the exobase. The altitude range is $50-432 \mathrm{~km}$. The chemical kinetics has been updated according to DeMore et al. [1987]. The solar flux we adopt corresponds to that appropriate for solar minimum condition [Rottman, 1981]. The model atmosphere above $120 \mathrm{~km}$ 
TABLE 1a. List of Essential Reactions for the Thermosphere With Their Preferred Rate Coefficients

\begin{tabular}{|c|c|c|c|}
\hline $\begin{array}{l}\text { Reaction } \\
\text { No. }\end{array}$ & Reaction & Rate Constant & Reference \\
\hline $\begin{array}{l}\text { (R1a) } \\
\text { (R1b) } \\
\text { (R2a) } \\
\text { (R2b) } \\
\text { (R3a) } \\
\text { (R3b) } \\
\text { (R3c) } \\
\text { (R4) } \\
\text { (R5) } \\
\text { (R6) } \\
\text { (R7a) } \\
\text { (R7b) } \\
\text { (R7c) } \\
\text { (R8) } \\
\text { (R9) } \\
\text { (R10) } \\
\text { (R11) } \\
\text { (R12) } \\
\text { (R13) } \\
\text { (R14) } \\
\text { (R15) } \\
\text { (R16) } \\
\text { (R17) } \\
\text { (R18) } \\
\text { (R19a) } \\
\text { (R19b) } \\
\text { (R19c) } \\
\text { (R20) } \\
\text { (R21) } \\
\text { (R22) } \\
\text { (R23) } \\
\text { (R24) } \\
\text { (R25) } \\
\text { (R26) } \\
\text { (R27) }\end{array}$ & 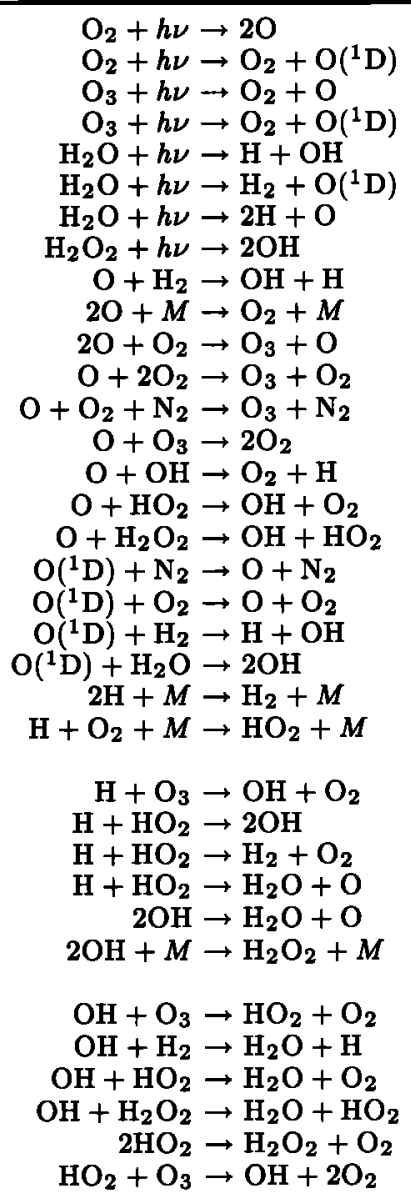 & $\begin{array}{c}4.8 \times 10^{-8} \\
1.6 \times 10^{-6} \\
9.0 \times 10^{-4} \\
5.7 \times 10^{-3} \\
5.5 \times 10^{-6} \\
3.8 \times 10^{-7} \\
4.5 \times 10^{-7} \\
6.8 \times 10^{-5} \\
1.6 \times 10^{-11} e^{-4570 / T} \\
4.3 \times 10^{-28} T^{-2} \\
6.4 \times 10^{-35} e^{663 / T} \\
6.4 \times 10^{-35} e^{663 / T} \\
5.0 \times 10^{-35} e^{724 / T} \\
8.0 \times 10^{-12} e^{-2060 / T} \\
2.2 \times 10^{-11} e^{120 / T} \\
3.0 \times 10^{-11} e^{200 / T} \\
1.4 \times 10^{-12} e^{-2000 / T} \\
1.8 \times 10^{-11} e^{110 / T} \\
3.2 \times 10^{-11} e^{70 / T} \\
1.0 \times 10^{-10} \\
2.2 \times 10^{-10} \\
1.0 \times 10^{-30} T^{-0.8} \\
k_{o}=5.7 \times 10^{-32}(300 / \mathrm{T})^{1.6} \\
k_{\infty}=7.5 \times 10^{-11} \\
1.4 \times 10^{-10} e^{-470 / T} \\
7.05 \times 10^{-11} \\
7.29 \times 10^{-12} \\
3.24 \times 10^{-12} \\
4.2 \times 10^{-12} e^{-240 / T} \\
k_{o}=6.9 \times 10^{-31}(300 / T)^{0.8} \\
k_{\infty}=1.0 \times 10^{-11}(300 / T) \\
1.6 \times 10^{-12} e^{-940 / T} \\
5.5 \times 10^{-12} e^{-2000 / T} \\
4.6 \times 10^{-11} e^{230 / T} \\
3.3 \times 10^{-12} e^{-200 / T} \\
2.3 \times 10^{-13} e^{600 / T} \\
1.1 \times 10^{-14} e^{-500 / T} \\
=100\end{array}$ & $\begin{array}{l}\mathrm{a} \\
\mathrm{a} \\
\mathrm{b} \\
\mathrm{b} \\
\mathrm{c} \\
\mathrm{c} \\
\mathrm{c} \\
\mathrm{d} \\
\mathrm{e} \\
\mathrm{e} \\
\mathbf{f} \\
\mathrm{f} \\
\mathrm{f} \\
\mathrm{g} \\
\mathrm{g} \\
\mathrm{g} \\
\mathrm{g} \\
\mathrm{g} \\
\mathrm{g} \\
\mathrm{g} \\
\mathrm{g} \\
\mathrm{h} \\
\mathrm{g} \\
\mathrm{g} \\
\mathrm{g} \\
\mathrm{g} \\
\mathbf{g} \\
\mathrm{g} \\
\mathrm{g} \\
\mathrm{g} \\
\mathrm{g} \\
\mathrm{g} \\
\mathrm{g} \\
\mathrm{g} \\
\mathrm{g} \\
\mathrm{g} \\
\mathrm{g}\end{array}$ \\
\hline
\end{tabular}

The units for mean photolysis rates $(J)$, and two-body and three-body reactions $(k)$ are $\mathrm{s}^{-1}, \mathrm{~cm}^{3} \mathrm{~s}^{-1}$, and $\mathrm{cm}^{6} \mathrm{~s}^{-1}$, respectively. The numerical values for photolysis refer to optically thin region. Reactions for deuterated species are included in Table $1 b$.

Reference citations are as follows: a, Kirby et al. [1979], Watanabe [1958], Ackerman [1971], Kley [1984], Hudson [1974], WMO [1985], Hudson and Reed [1979], Hudson and Mahle [1972], Prather [1981], Herman and Mentall [1982], Shardanand and Rao [1977], Carver et al. [1977]; b, Ackerman [1971], WMO [1985], DeMore et al. [1985]; c, Watanabe and Zelikoff [1953], Thompson et al. [1963], Kley [1984], Lee and Suto [1986], Haddad and Samson [1986], Slanger and Black [1982], Stief et al. [1975], Wu and Judge [1981]; d, Schürgers and Welge [1968], Climate Impact Assessment Program (CIAP) [1975], DeMore et al. [1985]; e, Hampson [1980]; f, Klais et al. [1980], Allen et al. [1984]; g, DeMore et al. [1987]; and h, Thainor et al. [1973].

was constructed self-consistently according to Bates [1959] and Chamberlain and Hunten [1987, appendix III] for the nonreacting species and by solving the continuity equation for the reactive species. The appropriate boundary conditions for the model are summarized in Table 2.

The exospheric temperature in midwinter 1974, when the relevant measurements of interest to this paper were made by the Atmosphere Explorer C, was $930 \mathrm{~K}$ [Breig et al., 1987]. At this temperature the thermal effusion velocities for $\mathrm{H}$ and $\mathrm{D}$ are 331 and $0.21 \mathrm{~cm} \mathrm{~s}^{-1}$, respectively. From previous experience with modeling $\mathrm{H}$ escape [Liu and Donahue, 1974a, $b, c]$, we expect the effective escape velocities for $H$ and $D$ to be much higher due to contributions from nonthermal processes. In this work we will take the effective escape velocities as unknown parameters, to be determined by requiring the model to reproduce the concentrations of $H$ and $D$ derived from observations. By trial and error we arrive at the appropriate escape velocities for $\mathrm{H}$ and $\mathrm{D}$ given in Table 2.

The continuity equations are solved for all important species in the model. Transport is parameterized by eddy diffusion, and we adopt the diffusivity profile of Allen et al. [1981]. The model is a diurnally averaged photochemical model for mid-latitude insolation. The numerical method is described by Allen et al. [1981]. In actual computation we first solved for the hydrogen species. Then we fixed the hydrogen species and solved for the deuterium species. The justification for this procedure is the fact that $\mathrm{D} / \mathrm{H} \ll 10^{-2}$ throughout the entire atmosphere, and hence the chemistry of deuterium has virtually no impact on that of hydrogen.

The temperature $T$ used in the model is given in Figure $2 a$. Altitude profiles for the eddy diffusivity $K$, and molecular diffusivity, $D_{H}$ (for hydrogen) and Do (for oxygen), in our model are shown in Figure $2 b$. Computed re- 
TABLE 1b. List of Essential Reactions for Deuterated Compounds

\begin{tabular}{|c|c|c|c|}
\hline $\begin{array}{c}\text { Reaction } \\
\text { No. }\end{array}$ & Reaction & Rate Constant & Reference \\
\hline $\begin{array}{l}\text { (R28a) } \\
\text { (R28b) } \\
(\text { R28c) } \\
(\text { R28d) } \\
(\text { R29) } \\
\text { (R30a) } \\
\text { (R30b) }\end{array}$ & $\begin{aligned} \mathrm{HDO}+\mathrm{h} \nu & \rightarrow \mathrm{H}+\mathrm{OD} \\
\mathrm{HDO}+\mathrm{h} \nu & \rightarrow \mathrm{D}+\mathrm{OH} \\
\mathrm{HDO}+\mathrm{h} \nu & \rightarrow \mathrm{HD}+\mathrm{O}\left({ }^{1} \mathrm{D}\right) \\
\mathrm{HDO}+\mathrm{h} \nu & \rightarrow \mathrm{H}+\mathrm{D}+\mathrm{O} \\
\mathrm{HDO}_{2}+\mathrm{h} \nu & \rightarrow \mathrm{OH}+\mathrm{OD} \\
\mathrm{O}+\mathrm{HD} & \rightarrow \mathrm{OH}+\mathrm{D} \\
\mathrm{O}+\mathrm{HD} & \rightarrow \mathrm{OD}+\mathrm{H}\end{aligned}$ & $\begin{array}{c}\frac{1}{2} J_{3 a} \\
\frac{1}{2} J_{3 a} \\
J_{3 b} \\
J_{3 c} \\
J_{4} \\
k_{a}+k_{b}=1.74 \times 10^{-12} e^{-4050 / T} \\
\frac{k_{a}}{k_{b}}=0.5 e^{-750 / T}\end{array}$ & $\begin{array}{l}\mathrm{a} \\
\mathrm{a} \\
\mathrm{b} \\
\mathrm{b} \\
\mathrm{a} \\
\mathrm{c} \\
\mathrm{c}\end{array}$ \\
\hline (R31) & $\mathrm{OH}+\mathrm{D} \rightarrow \mathrm{OD}+\mathrm{H}$ & $3.3 \times 10^{-9} T^{-0.63}$ & d \\
\hline $\begin{array}{l}(\mathbf{R 3 2}) \\
(\mathbf{R 3 3})\end{array}$ & $\begin{array}{c}\mathrm{OD}+\mathrm{H} \rightarrow \mathrm{OH}+\mathrm{D} \\
\mathrm{D}+\mathrm{HO}_{2} \rightarrow \mathrm{DO}_{2}+\mathrm{H}\end{array}$ & $\begin{array}{c}4.58 \times 10^{-9} T^{-0.63} e^{-717 / T} \\
1.0 \times 10^{-10}\end{array}$ & $\begin{array}{l}d \\
d\end{array}$ \\
\hline (R34) & $\mathrm{H}+\mathrm{DO}_{2} \rightarrow \mathrm{HO}_{2}+\mathrm{D}$ & $1.85 \times 10^{-10} e^{-890 / T}$ & $\begin{array}{l}d \\
d\end{array}$ \\
\hline (R35) & $\mathrm{O}+\mathrm{OD} \rightarrow \mathrm{O}_{2}+\mathrm{D}$ & $k_{9}$ & a \\
\hline $\begin{array}{l}\text { (R36) } \\
\text { (R37a) }\end{array}$ & $\begin{array}{c}\mathrm{O}+\mathrm{DO}_{2} \rightarrow \mathrm{OD}+\mathrm{O}_{2} \\
\mathrm{O}+\mathrm{HDO}_{2} \rightarrow \mathrm{OD}+\mathrm{HO}_{2}\end{array}$ & $\begin{array}{l}k_{10} \\
\frac{1}{n} k_{11}\end{array}$ & $\begin{array}{l}\mathrm{a} \\
\mathrm{b}\end{array}$ \\
\hline (R37b) & $\mathrm{O}+\mathrm{HDO}_{2} \rightarrow \mathrm{OH}+\mathrm{DO}_{2}$ & $\begin{array}{l}2 \\
\frac{1}{2} \\
n_{11}\end{array}$ & $\mathrm{~b}$ \\
\hline (R38a) & $\mathrm{O}\left({ }^{1} \mathrm{D}\right)+\mathrm{HD} \rightarrow \mathrm{H}+\mathrm{OD}$ & $0.41\left(k_{14}\right)$ & $\mathrm{b}$ \\
\hline (R38b) & $\mathrm{O}\left({ }^{1} \mathrm{D}\right)+\mathrm{HD} \rightarrow \mathrm{D}+\mathrm{OH}$ & $0.41\left(k_{14}\right)$ & b \\
\hline (R39) & $\mathrm{O}\left({ }^{1} \mathrm{D}\right)+\mathrm{HDO} \rightarrow \mathrm{OD}+\mathrm{OH}$ & $k_{15}$ & a \\
\hline$(\mathbf{R 4 0})$ & $\mathrm{H}+\mathrm{D}+M \rightarrow \mathrm{HD}+M$ & $k_{16}$ & a \\
\hline $\begin{array}{l}(\mathbf{R 4 1}) \\
(\mathbf{R 4 2})\end{array}$ & $\begin{aligned} \mathrm{D}+\mathrm{O}_{2}+M & \rightarrow \mathrm{DO}_{2}+M \\
\mathrm{D}+\mathrm{O}_{3} & \rightarrow \mathrm{OD}+\mathrm{O}_{2}\end{aligned}$ & $\begin{array}{c}k_{17} \\
0.71\left(k_{18}\right)\end{array}$ & $\begin{array}{l}\mathrm{a} \\
\mathrm{b}\end{array}$ \\
\hline (R43a) & $\mathrm{D}+\mathrm{HO}_{2} \rightarrow \mathrm{OH}+\mathrm{OD}$ & $0.71\left(k_{19 a}\right)$ & $\mathrm{b}$ \\
\hline (R43b) & $\mathrm{D}+\mathrm{HO}_{2} \rightarrow \mathrm{HD}+\mathrm{O}_{2}$ & $0.71\left(k_{19 b}\right)$ & $\mathrm{b}$ \\
\hline (R43c) & $\mathrm{D}+\mathrm{HO}_{2} \rightarrow \mathrm{HDO}+\mathrm{O}$ & $0.71\left(k_{19 c}\right)$ & $\mathrm{b}$ \\
\hline (R44a) & $\mathrm{H}+\mathrm{DO}_{2} \rightarrow \mathrm{OH}+\mathrm{OD}$ & $k_{19 a}$ & $\mathbf{a}$ \\
\hline (R44b) & $\mathrm{H}+\mathrm{DO}_{2} \rightarrow \mathrm{HD}+\mathrm{O}_{2}$ & $k_{19 b}$ & a \\
\hline$(\mathrm{R} 44 \mathrm{c})$ & $\mathrm{H}+\mathrm{DO}_{2} \rightarrow \mathrm{HDO}+\mathrm{O}$ & $k_{19 c}$ & $\mathrm{a}$ \\
\hline (R45) & $\mathrm{OD}+\mathrm{OH} \rightarrow \mathrm{HDO}+\mathrm{O}$ & $k_{20}$ & a \\
\hline (R46) & $\mathrm{OD}+\mathrm{OH}+M \rightarrow \mathrm{HDO}_{2}+M$ & $k_{21}$ & $\mathrm{a}$ \\
\hline (R47) & $\mathrm{OD}+\mathrm{O}_{3} \rightarrow \mathrm{DO}_{2}+\mathrm{O}_{2}$ & $k_{22}$ & a \\
\hline (R48a) & $\mathrm{OD}+\mathrm{H}_{2} \rightarrow \mathrm{HDO}+\mathrm{H}$ & $k_{23}$ & $\mathrm{~b}$ \\
\hline (R48b) & $\mathrm{OD}+\mathrm{H}_{2} \rightarrow \mathrm{H}_{2} \mathrm{O}+\mathrm{D}$ & 0 & $\mathrm{~b}$ \\
\hline (R49a) & $\mathrm{OH}+\mathrm{HD} \rightarrow \mathrm{HDO}+\mathrm{H}$ & $\frac{3}{20} k_{23}$ & e \\
\hline (R49b) & $\mathrm{OH}+\mathrm{HD} \rightarrow \mathrm{H}_{2} \mathrm{O}+\mathrm{D}$ & $\frac{3}{20} k_{23}$ & e \\
\hline (R50) & $\mathrm{H}+\mathrm{HD} \rightarrow \mathrm{H}_{2}+\mathrm{D}$ & $6.31 \times 10^{-11} e^{-4038 / T}$ & $\mathrm{~b}$ \\
\hline (R51) & $\mathrm{D}+\mathrm{H}_{2} \rightarrow \mathrm{HD}+\mathrm{H}$ & $6.31 \times 10^{-11} e^{-3821 / T}$ & $\mathrm{~b}$ \\
\hline (R52) & $\mathrm{OD}+\mathrm{HO}_{2} \rightarrow \mathrm{HDO}+\mathrm{O}_{2}$ & $k_{24}$ & a \\
\hline (R53) & $\mathrm{OH}+\mathrm{DO}_{2} \rightarrow \mathrm{HDO}+\mathrm{O}_{2}$ & $k_{24}$ & a \\
\hline (R54) & $\mathrm{DO}_{2}+\mathrm{O}_{3} \rightarrow \mathrm{OD}+2 \mathrm{O}_{2}$ & $k_{27}$ & $\mathrm{a}$ \\
\hline (R55a) & $\mathrm{OD}+\mathrm{H}_{2} \mathrm{O}_{2} \rightarrow \mathrm{HDO}+\mathrm{HO}_{2}$ & $k_{25}$ & $\mathrm{~b}$ \\
\hline (R55b) & $\mathrm{OD}+\mathrm{H}_{2} \mathrm{O}_{2} \rightarrow \mathrm{H}_{2} \mathrm{O}+\mathrm{DO}_{2}$ & 0 & b \\
\hline (R56a) & $\mathrm{OH}+\mathrm{HDO}_{2} \rightarrow \mathrm{HDO}+\mathrm{HO}_{2}$ & $\frac{1}{2} k_{25}$ & a \\
\hline (R56b) & $\mathrm{OH}+\mathrm{HDO}_{2} \rightarrow \mathrm{H}_{2} \mathrm{O}+\mathrm{DO}_{2}$ & $\frac{1}{2} k_{25}$ & a \\
\hline (R57) & $\mathrm{DO}_{2}+\mathrm{HO}_{2} \rightarrow \mathrm{HDO}_{2}+\mathrm{O}_{2}$ & $k_{26}$ & a \\
\hline
\end{tabular}

References citations are as follows: a, Kasting and Pollack [1983]; b, assumed; c, Garrett et al. [1986]; d, Yung et al. [1988]; e, estimate based on Ravshankara et al. [1981].

sults from our standard model for the total number density, $n$, and the nonhydrogen species, $\mathrm{N}_{2}, \mathrm{O}_{2}, \mathrm{O}, \mathrm{Ar}, \mathrm{He}$, $\mathrm{O}_{3}$, and $\mathrm{O}\left({ }^{1} \mathrm{D}\right)$, are shown in Figure 3. The concentrations of hydrogen species, $\mathrm{H}_{2} \mathrm{O}, \mathrm{H}, \mathrm{OH}, \mathrm{HO}_{2}, \mathrm{H}_{2} \mathrm{O}_{2}$, and $\mathrm{H}_{2}$, are given in Figure 4. Figure $5 a$ presents both the major reactions which control the loss of $\mathrm{H}_{2} \mathrm{O}$, (R3) $\mathrm{H}_{2} \mathrm{O}+\mathrm{h} \nu$, (R15) $\mathrm{O}\left({ }^{1} \mathrm{D}\right)+\mathrm{H}_{2} \mathrm{O}$, and the major reaction that results in production of $\mathrm{H}_{2} \mathrm{O},(\mathrm{R} 24) \mathrm{OH}+\mathrm{HO}_{2}$. (Note that in Figures 5, 6, 8, and 9 we only present results from 50 to $200 \mathrm{~km}$, although all computations were carried out from 50 to $432 \mathrm{~km}$.) The column-integrated destruction rate is $1.02 \times 10^{10} \mathrm{~cm}^{-2} \mathrm{~s}^{-1}$. The corresponding producing rate is $8.82 \times 10^{9} \mathrm{~cm}^{-2} \mathrm{~s}^{-1}$. Therefore nearly $90 \%$ of $\mathrm{H}_{2} \mathrm{O}$ destruction leads back to $\mathrm{H}_{2} \mathrm{O}$. Only about $10 \%$ is converted to $\mathrm{H}_{2}$. Figure $5 b$ presents the major reactions which produce $\mathrm{H}_{2},(\mathrm{R} 19 \mathrm{~b}) \mathrm{H}+\mathrm{HO}_{2},(\mathrm{R} 3 \mathrm{~b}) \mathrm{H}_{2} \mathrm{O}+\mathrm{h} \nu$, and reactions which destroy $\mathrm{H}_{2}$, (R5) $\mathrm{H}_{2}+\mathrm{O}$, (R14) $\mathrm{H}_{2}+\mathrm{O}\left({ }^{1} \mathrm{D}\right)$, (R23) $\mathrm{H}_{2}+\mathrm{OH}$. $\mathrm{H}_{2}$ serves as a carrier of hydrogen to the upper atmosphere above $100 \mathrm{~km}$. Above $150 \mathrm{~km}$ the molecule is not stable against (R5) and (R14) and is readily converted to $\mathrm{H}$. The fluxes of the long-lived hydrogen species, $\mathrm{H}_{2} \mathrm{O}, \mathrm{H}$, and $\mathrm{H}_{2}$ are shown in Figure 6. In the lower atmosphere (below $100 \mathrm{~km}$ ) the major carrier of hydrogen flow is $\mathrm{H}_{2} \mathrm{O}$. In the upper atmosphere (above $100 \mathrm{~km}$ ) the major carriers are $\mathrm{H}$ and $\mathrm{H}_{2}$. The flow of $\mathrm{H}_{2} \mathrm{O}$ in the model is always upward. $\mathrm{H}$ and $\mathrm{H}_{2}$, produced primarily between 80 and $100 \mathrm{~km}$, can flow both upward and downward. These results generally reproduce the computations of Liu and Donahue [1974a], where our models overlap (Liu and Donahue's model has an upper boundary at $140 \mathrm{~km}$ ), and support the overall picture of hydrogen escape described in the previous section. Minor differences may be attributed to the updating of chemical kinetics.

The computed results of the deuterated species HDO, D, $\mathrm{OD}, \mathrm{DO}_{2}, \mathrm{HDO}_{2}$, and $\mathrm{HD}$ are summarized in Figure 7. The major destruction reactions for $\mathrm{HDO},(\mathrm{R} 28) \mathrm{HDO}+\mathrm{h} \nu$, 
TABLE 2. Boundary Conditions for the Standard Model

\begin{tabular}{|c|c|c|}
\hline Species & $\begin{array}{c}\text { Lower Boundary } \\
(50 \mathrm{~km})\end{array}$ & $\begin{array}{l}\text { Upper Boundary } \\
(432 \mathrm{~km})\end{array}$ \\
\hline $\begin{array}{c}\mathrm{N}_{2} \\
\mathrm{O} \\
\mathrm{O}\left({ }^{1} \mathrm{D}\right) \\
\mathrm{O}_{2} \\
\mathrm{O}_{3} \\
\mathrm{H} \\
\mathrm{H}_{2} \\
\mathrm{OH} \\
\mathrm{HO}_{2} \\
\mathrm{H}_{2} \mathrm{O}_{2} \\
\mathrm{H}_{2} \mathrm{O} \\
\mathrm{D} \\
\mathrm{HD} \\
\mathrm{OD} \\
\mathrm{DO} \\
\mathrm{HDO} \\
\mathrm{HDO} \\
\mathrm{He} \\
\mathrm{Ar}\end{array}$ & $\begin{array}{c}f=0.781 \\
\phi=0 \\
\phi=0 \\
f=0.209 \\
f=2.2 \times 10^{-6} \\
\phi=0 \\
f=5.9 \times 10^{-7} \\
\phi=0 \\
\phi=0 \\
f=5.0 \times 10^{-11} \\
f=7.0 \times 10^{-6} \\
\phi=0 \\
f=1.6 \times 10^{-10} \\
\phi=0 \\
\phi=0 \\
\phi=0 \\
f=2.2 \times 10^{-9} \\
5.2 \times 10^{-6} \\
9.3 \times 10^{-3}\end{array}$ & $\begin{array}{c}\phi=0 \\
\phi=0 \\
\phi=0 \\
\phi=0 \\
\phi=0 \\
v=1.4 \times 10^{3} \\
v=0.21 \\
\phi=0 \\
\phi=0 \\
\phi=0 \\
\phi=0 \\
v=1.9 \times 10^{2} \\
v=1.2 \times 10^{-4} \\
\phi=0 \\
\phi=0 \\
\phi=0 \\
\phi=0 \\
\phi=0 \\
\phi=0\end{array}$ \\
\hline
\end{tabular}

There are types of boundary conditions. We can specify the mixing ratio $f$, the flux $\phi\left(\mathrm{cm}^{-2} \mathrm{~s}^{-1}\right)$, or the escape velocity $v\left(\mathrm{~cm} \mathrm{~s}^{-1}\right)$. The abundances for $\mathrm{H}_{2} \mathrm{O}$ and $\mathrm{HDO}$ include contributions from $\mathrm{CH}_{4}$ and $\mathrm{CH}_{3} \mathrm{D}$, respectively. The effective escape velocities for $\mathrm{H}$ and $\mathrm{D}$ are obtained by matching the model to the observations; those for $\mathrm{H}_{2}$ and $\mathrm{HD}$ are thermal effusion velocities.

(R39) $\mathrm{HDO}+\mathrm{O}\left({ }^{1} \mathrm{D}\right)$, and the major production reactions, (R52) $\mathrm{OD}+\mathrm{HO}_{2}$, (R53) $\mathrm{OH}+\mathrm{DO}_{2}$, are shown in Figure $8 a$. Figure $8 b$ presents the main reactions for producing $\mathrm{HD},(\mathrm{R} 43 \mathrm{~b}) \mathrm{D}+\mathrm{HO}_{2},(\mathrm{R} 44 \mathrm{~b}) \mathrm{H}+\mathrm{DO}_{2},(\mathrm{R} 28 \mathrm{c}) \mathrm{HDO}+\mathrm{h} \nu$, and for destroying $\mathrm{HD}$, (R30) $\mathrm{HD}+\mathrm{O}$, (R38) $\mathrm{HD}+\mathrm{O}\left({ }^{1} \mathrm{D}\right)$, (R49) HD + OH. Figure 9 gives the fluxes of the major deuterium species $\mathrm{HDO}, \mathrm{D}$, and $\mathrm{HD}$.
A summary of the essential aspects of the model and results for hydrogen and deuterium are given in Table $3 a$. There is a minor discrepancy between the altitude for the exobase $\left(n=4.7 \times 10^{7} \mathrm{~cm}^{-3}\right.$; see Chamberlain and Hunten [1987], for definition) computed in our model and that of Breig et al. [1987]. This discrepancy is caused by the way that the temperature profile (see Figure $2 a$ ) is interpolated between the exosphere and the mesosphere. This slight displacement of $30 \mathrm{~km}$ does not affect the principal results of our model.

Numerous runs were carried out to test the sensitivity of our model to key assumptions. The reactions,

$$
\begin{aligned}
\mathrm{OH}+\mathrm{HO}_{2} & \rightarrow \mathrm{H}_{2} \mathrm{O}+\mathrm{O}_{2} \\
\mathrm{H}+\mathrm{HO}_{2} & \rightarrow \mathrm{H}_{2}+\mathrm{O}_{2} \\
\mathrm{O}+\mathrm{H}_{2} & \rightarrow \mathrm{OH}+\mathrm{H}
\end{aligned}
$$

respectively, play a fundamental role in the conversion of hydrogen-containing radicals to $\mathrm{H}_{2} \mathrm{O}$, in producing $\mathrm{H}_{2}$, and in destroying $\mathrm{H}_{2}$. When the rate coefficients, $k_{24}, k_{19 b}$, and $k_{5}$ were each varied by a factor of 2 in the standard model, the magnitude of the hydrogen escape flux varied by less than $1 \%$. We note that these reactions do not result in a net change in the total hydrogen content of the atmosphere. Hence by Hunten's limiting flux theorem, they have no impact on the escape flux. We also carried out runs varying the eddy diffusivity profile by factors of 2 . The resulting fluxes varied by less than $1 \%$. However, when we increased the molecular diffusivity profile for $\mathrm{H}$ and $\mathrm{H}_{2}$ by a factor of 2 , there was a corresponding factor of 2 increase in the escape flux. Again, these results are in agreement with the predictions of Hunten's theorem and demonstrate that the escape

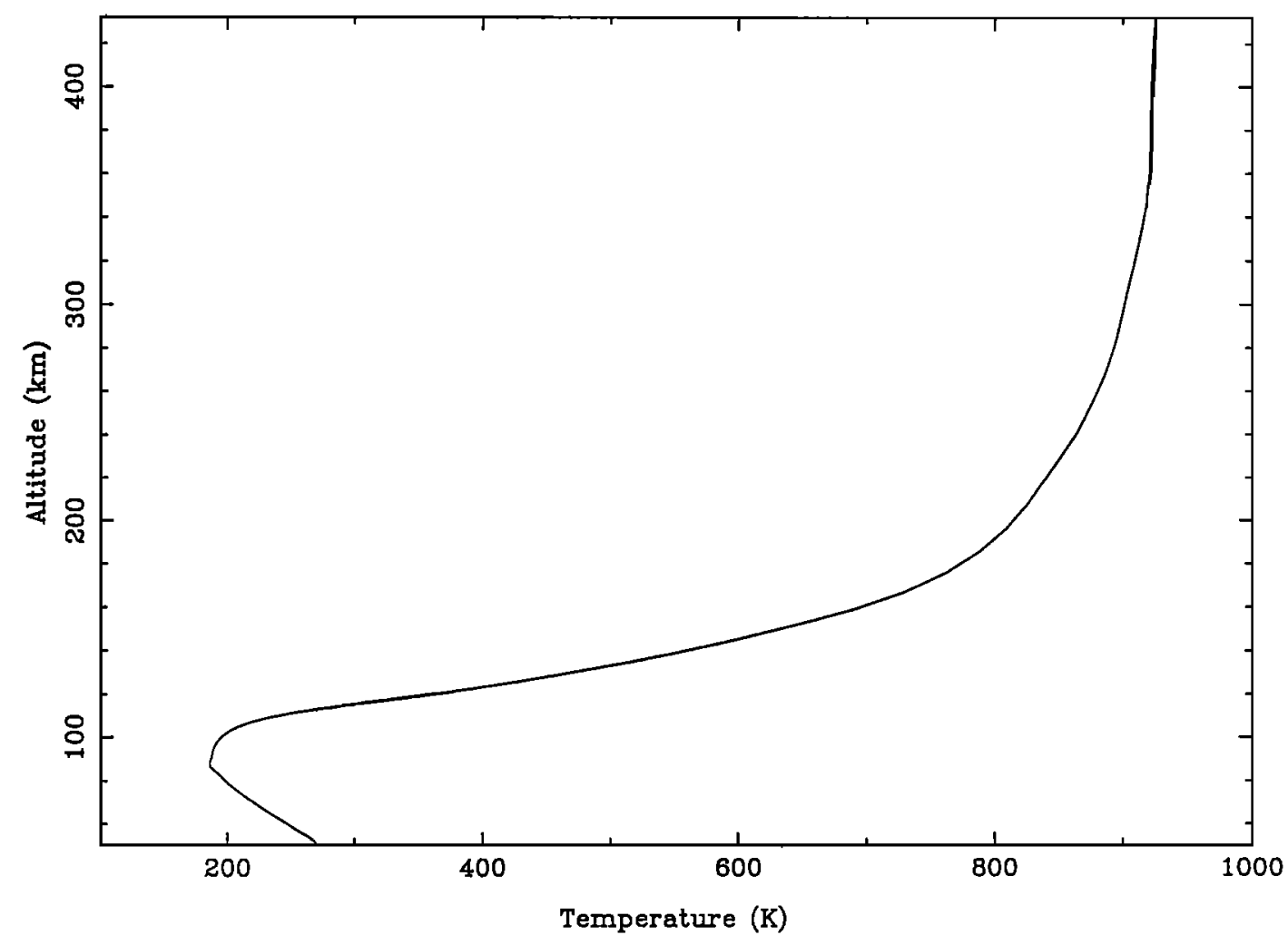

Fig. 2a. Altitude profile of temperature, T, adopted for the model. exosphere is $930 \mathrm{~K}$. 


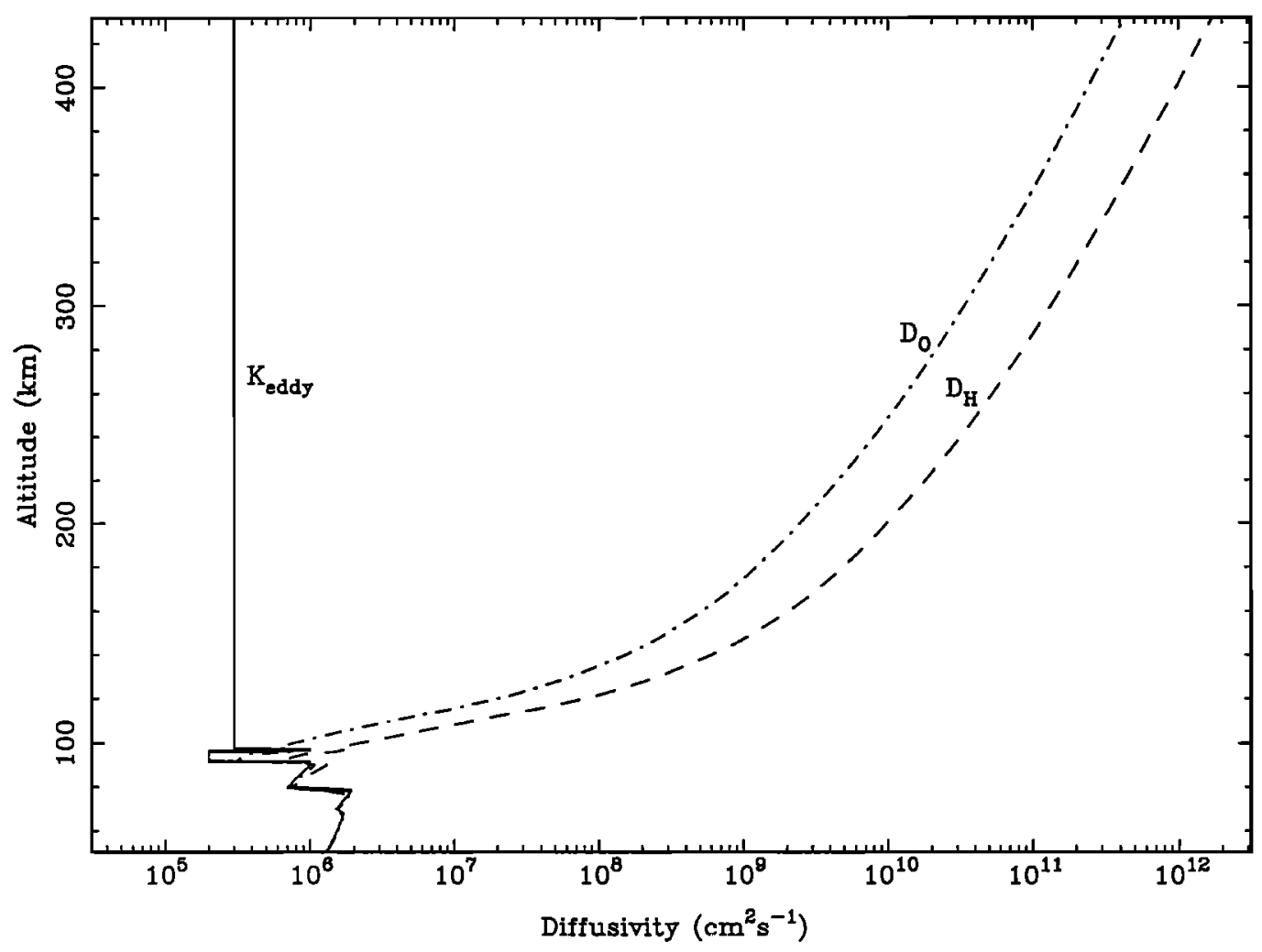

Fig. 2b. Altitude profiles of eddy diffusivity $K$ and molecular diffusivity $\mathrm{D}_{\mathrm{H}}$ (for $\mathrm{H}$ ) and $\mathrm{D}_{\mathrm{O}}$ (for $\mathrm{O}$ ).

fluxes computed by our model are robust results, largely independent of the detailed chemistry in the model.

\section{THERMAL ESCAPE}

The effusion velocity predicted by Jeans formula is

$$
\langle v\rangle=B \frac{v_{t h}}{2 \sqrt{\pi}}(1+\lambda) e^{-\lambda}
$$

where

$$
\begin{gathered}
v_{t h}=\sqrt{\frac{2 k T}{m}} \\
\lambda=\frac{G M m}{k T r}
\end{gathered}
$$

and the symbols have their usual meanings [Chamberlain and Hunten, 1987). The efficiency factor B equals 0.72 for hydrogen escaping from an O-atom-dominated exobase [Chamberlain and Smith, 1971; Hunten and Donahue, 1976] and the same value is adopted for deuterium. Using this formula, we obtain velocities 331 and $0.21 \mathrm{~cm} \mathrm{~s}^{-1}$, for $H$ and $D$, respectively. These values are significantly lower than the corresponding effective escape velocities $1.4 \times 10^{3}$ and 190 $\mathrm{cm} \mathrm{s}^{-1}$ deduced, in the previous section. Therefore we conclude that the escape of $H$ and $D$ is primarily nonthermal. The reason is that the exospheric temperature $T_{e}$ is relatively low $(930 \mathrm{~K})$. The same conclusion is not true at solar maximum, when $T_{e}$ is $1500 \mathrm{~K}$ [Liu and Donahue, 1974b].

In order to understand the sensitivity of our results to the assumed effective escape velocities for $H$ and $D$, we ran a large number of cases with different velocities. The re- sults for the fluxes and concentrations of $H$ and $D$ at the exobase as a function of escape velocity are summarized in Figures $10 a$ and $10 b$. It is clear from these results that Hunten's limiting flux for hydrogen is attained over a wide range of escape velocities near those used in the standard model. The limiting flux is marginally attained by $\mathrm{D}$ in the standard model. A significant drop in the escape velocity would have an impact on the flux of $D$. The important fluxes are defined and summarized in Table $3 b$.

Our hydrogen escape flux, $\phi_{1}(\mathrm{H})=3.02 \times 10^{8} \mathrm{~cm}^{-2} \mathrm{~s}^{-1}$, based on total hydrogen mixing ratio $f_{t}=15.2 \mathrm{ppm}$ at $50 \mathrm{~km}$, is in good agreement with the flux $2.68 \times 10^{8} \mathrm{~cm}^{-2}$ $\mathrm{s}^{-1}$, computed by Liu and Donahue $[1974 \mathrm{c}]$ in a model with $f_{t}=14.8 \mathrm{ppm}$ at $50 \mathrm{~km}$. In our model the sphericity of the atmosphere is taken into account. Unless otherwise stated, all our fluxes are per square centimeter of the surface of the Earth. There is no mention of a sphericity correction in the work of Liu and Donahue. Therefore assuming that their flux was computed for the exobase, we obtain a flux of $3.06 \times 10^{8} \mathrm{~cm}^{-2} \mathrm{~s}^{-1}$, referred to the surface, in complete agreement with our result. However, our deduced thermal flux at $926 \mathrm{~K}, \phi_{2}(\mathrm{H})=7.14 \times 10^{7} \mathrm{~cm}^{-2} \mathrm{~s}^{-1}$, is higher than that deduced by Liu and Donahue [1974b] for $950 \mathrm{~K}$, $3.67 \times 10^{7} \mathrm{~cm}^{-2} \mathrm{~s}^{-1}$. The discrepancy may be attributed to the inaccuracy in the number density of $\mathrm{H}$ deduced using Ly $\alpha$ observations of Bertaux [1975] and Vidal-Madjar et al. [1974]. In our study we use the number density of $H$ and the exospheric temperature reported by Breig et al. [1987] on the basis of mass-spectrometric measurements. We believe that the in-situ measurements of $\mathrm{H}$ are more accurate than those deduced from remote sensing using scattered radiation. Our major conclusions regarding the escape of D 


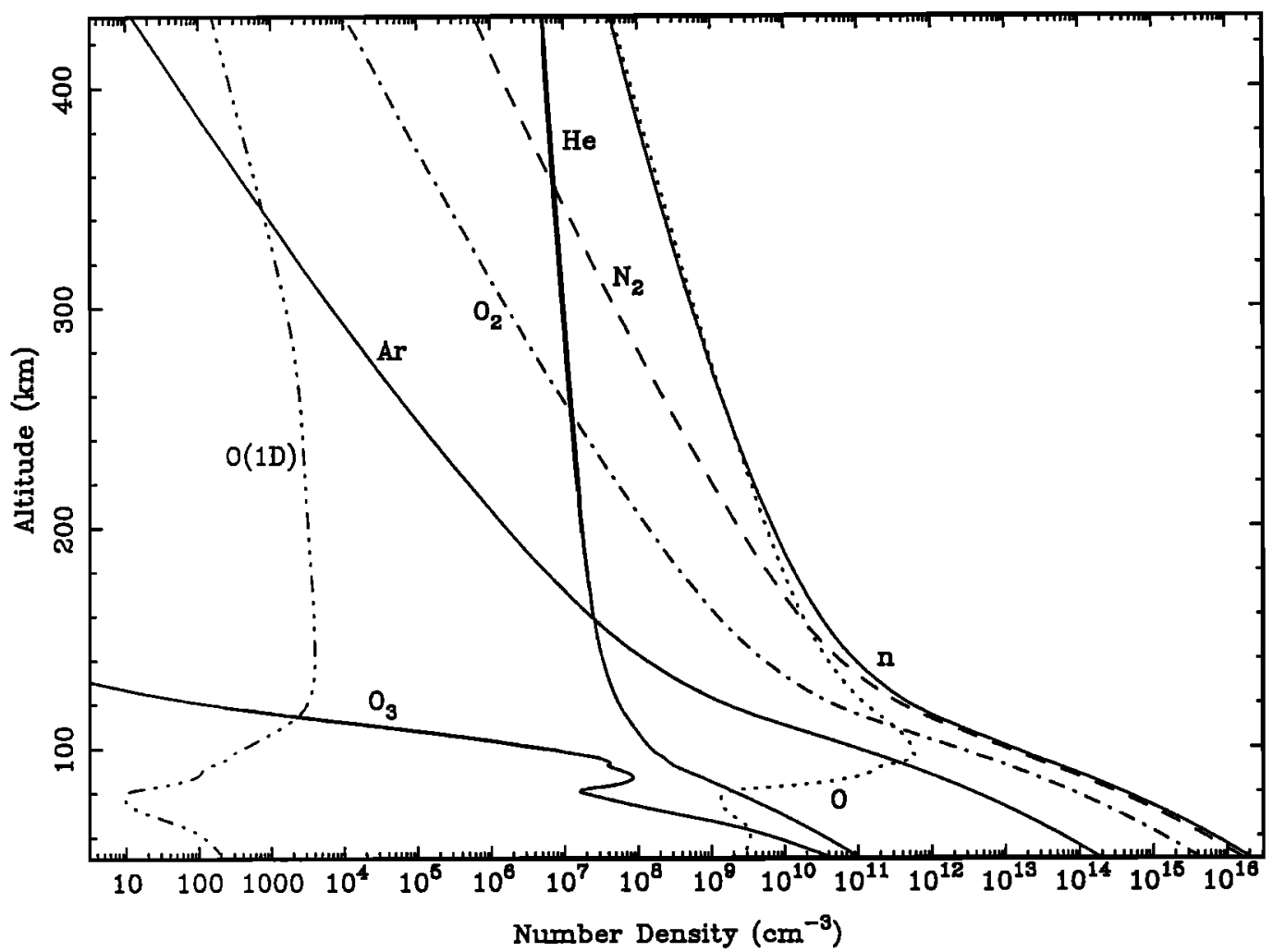

Fig. 3. Altitude profiles of concentrations of total number density $n$, and nonhydrogen species, $\mathrm{N}_{2}, \mathrm{O}_{2}, \mathrm{O}, \mathrm{Ar}$, $\mathrm{He}, \mathrm{O}_{3}$, and $\mathrm{O}\left({ }^{1} \mathrm{D}\right)$ computed in our model.

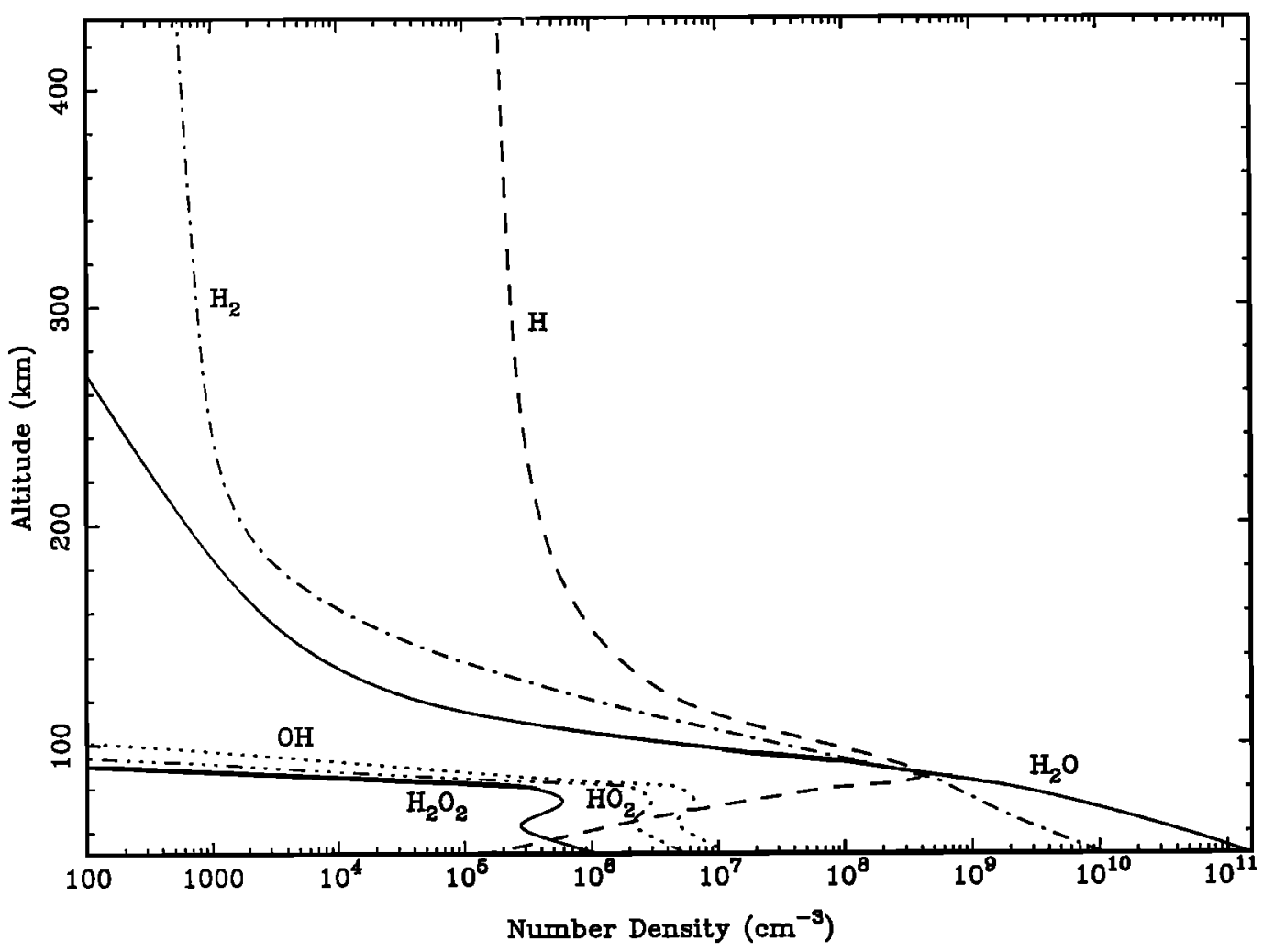

Fig. 4. Same as Figure 3, except for hydrogen species $\mathrm{H}_{2} \mathrm{O}, \mathrm{H}, \mathrm{OH}, \mathrm{HO}_{2}, \mathrm{H}_{2} \mathrm{O}_{2}$, and $\mathrm{H}_{2}$. 


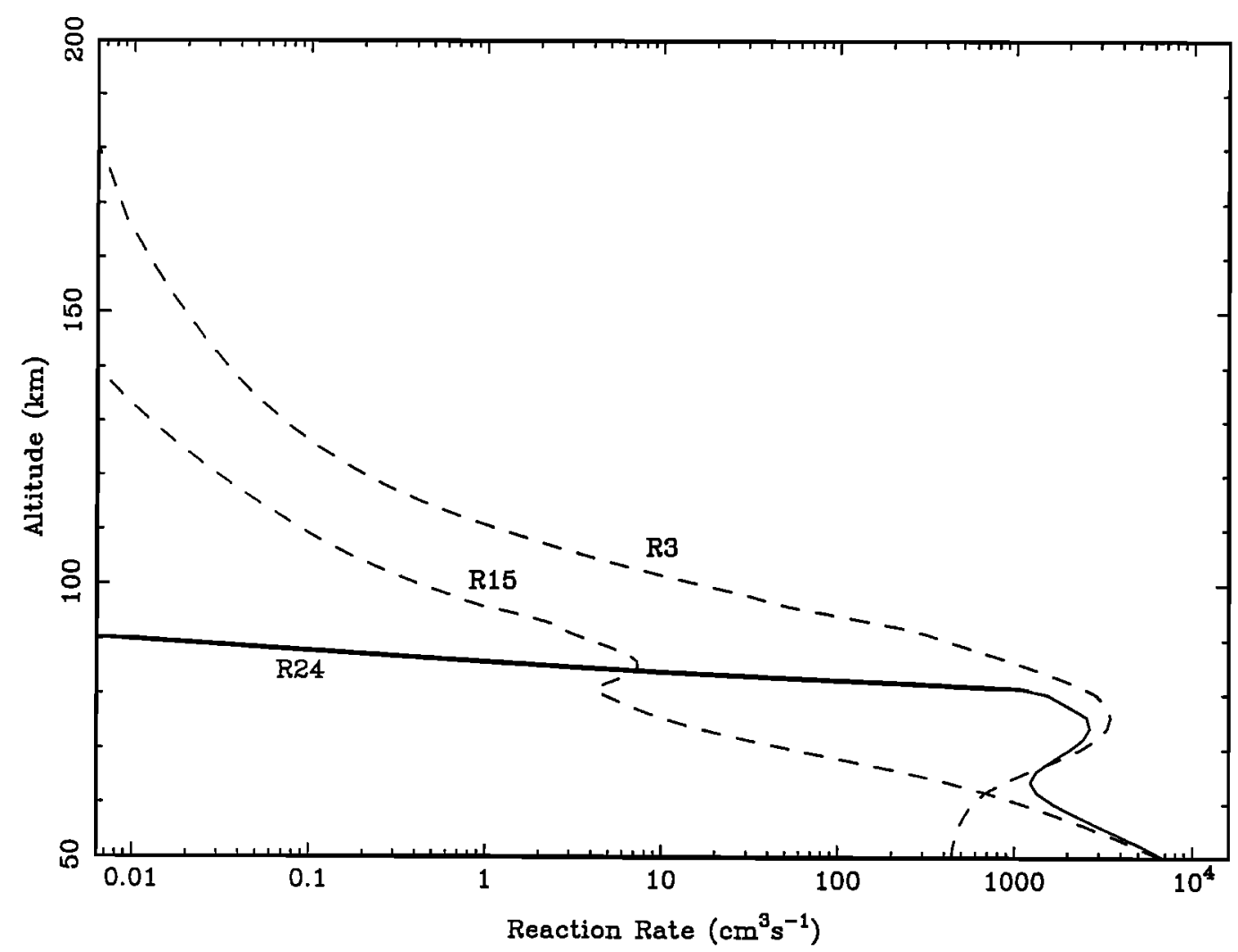

Fig. 5a. Reaction rates for the major reactions which destroy $\mathrm{H}_{2} \mathrm{O}$ : (R3) $\mathrm{H}_{2} \mathrm{O}+\mathrm{h} \nu \rightarrow$ products, $(\mathrm{R} 15) \mathrm{H}_{2} \mathrm{O}+\mathrm{O}$ ( $\left.{ }^{1} \mathrm{D}\right) \rightarrow$ products; the major reaction which produces $\mathrm{H}_{2} \mathrm{O}:$ (R.24) $\mathrm{OH}+\mathrm{HO}_{2} \rightarrow \mathrm{H}_{2} \mathrm{O}+\mathrm{O}_{2}$.

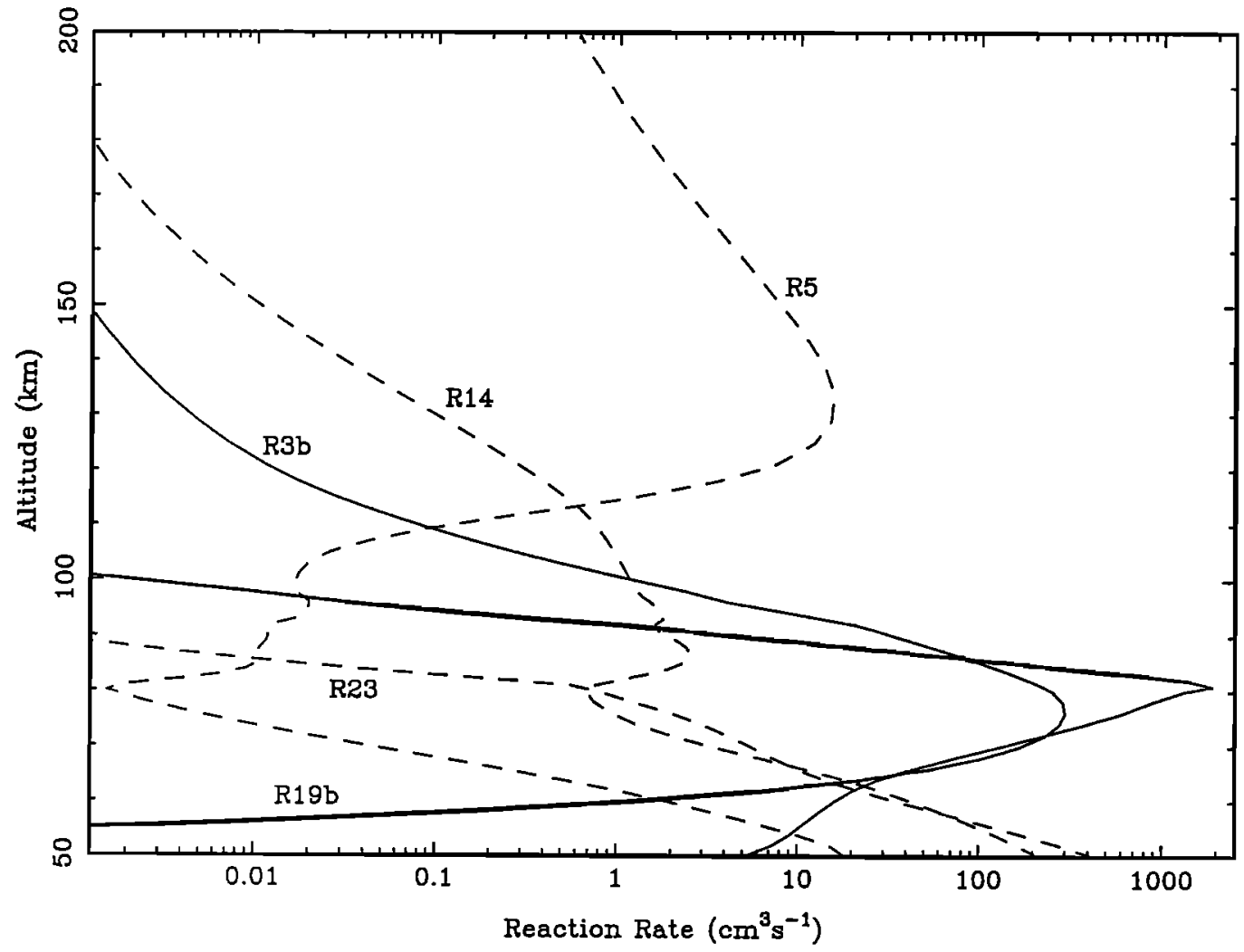

Fig. 5b. Same as Figure 5a, except for $\mathrm{H}_{2}$. Major reactions destroying $\mathrm{H}_{2}$ : (R5) $\mathrm{H}_{2}+\mathrm{O} \rightarrow$ products, (R14) $\mathrm{H}_{2}+\mathrm{O}\left({ }^{1} \mathrm{D}\right) \rightarrow$ products, (R23) $\mathrm{H}_{2}+\mathrm{OH} \rightarrow$ products; major reactions producing $\mathrm{H}_{2}:(\mathrm{R} 19 \mathrm{~b}) \mathrm{H}+\mathrm{HO}_{2} \rightarrow \mathrm{H}_{2}+$ $\mathrm{O}_{2}$ and (R3b) $\mathrm{H}_{2} \mathrm{O}+\mathrm{h} \nu \rightarrow \mathrm{H}_{2}+\mathrm{O}\left({ }^{1} \mathrm{D}\right)$. 


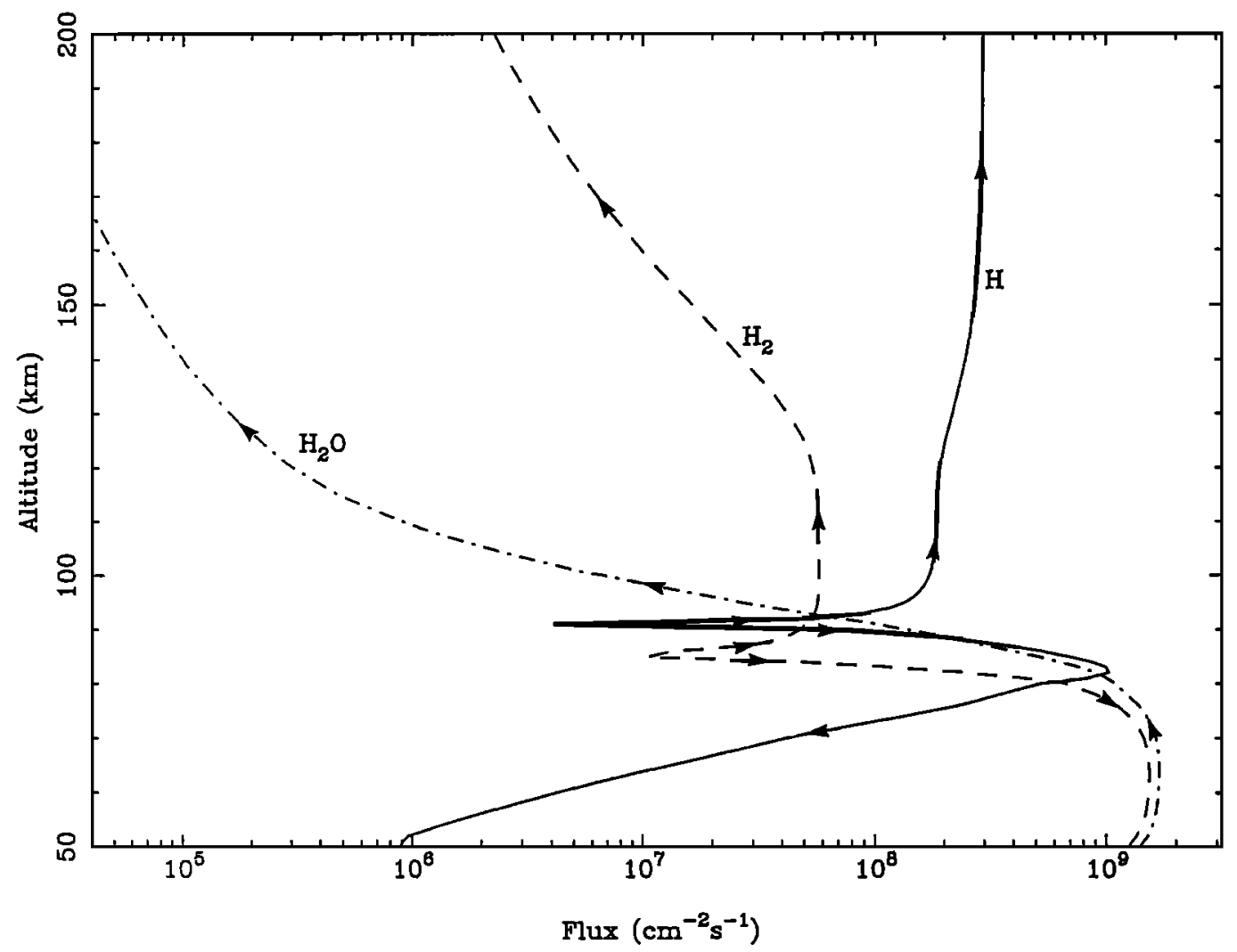

Fig. 6. Fluxes of the major hydrogen species.

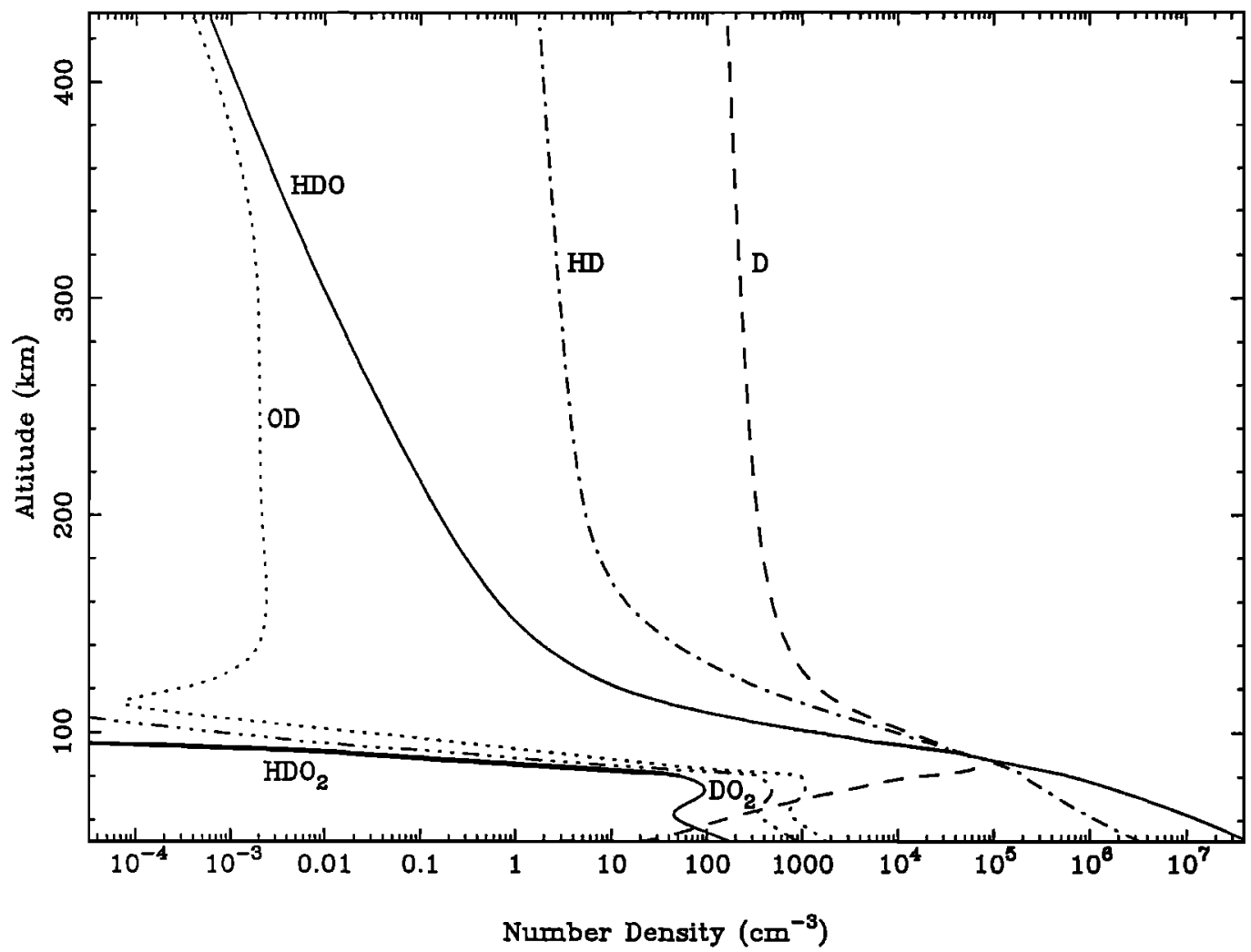

Fig. 7. Same as Figure 4, except for deuterium species. 


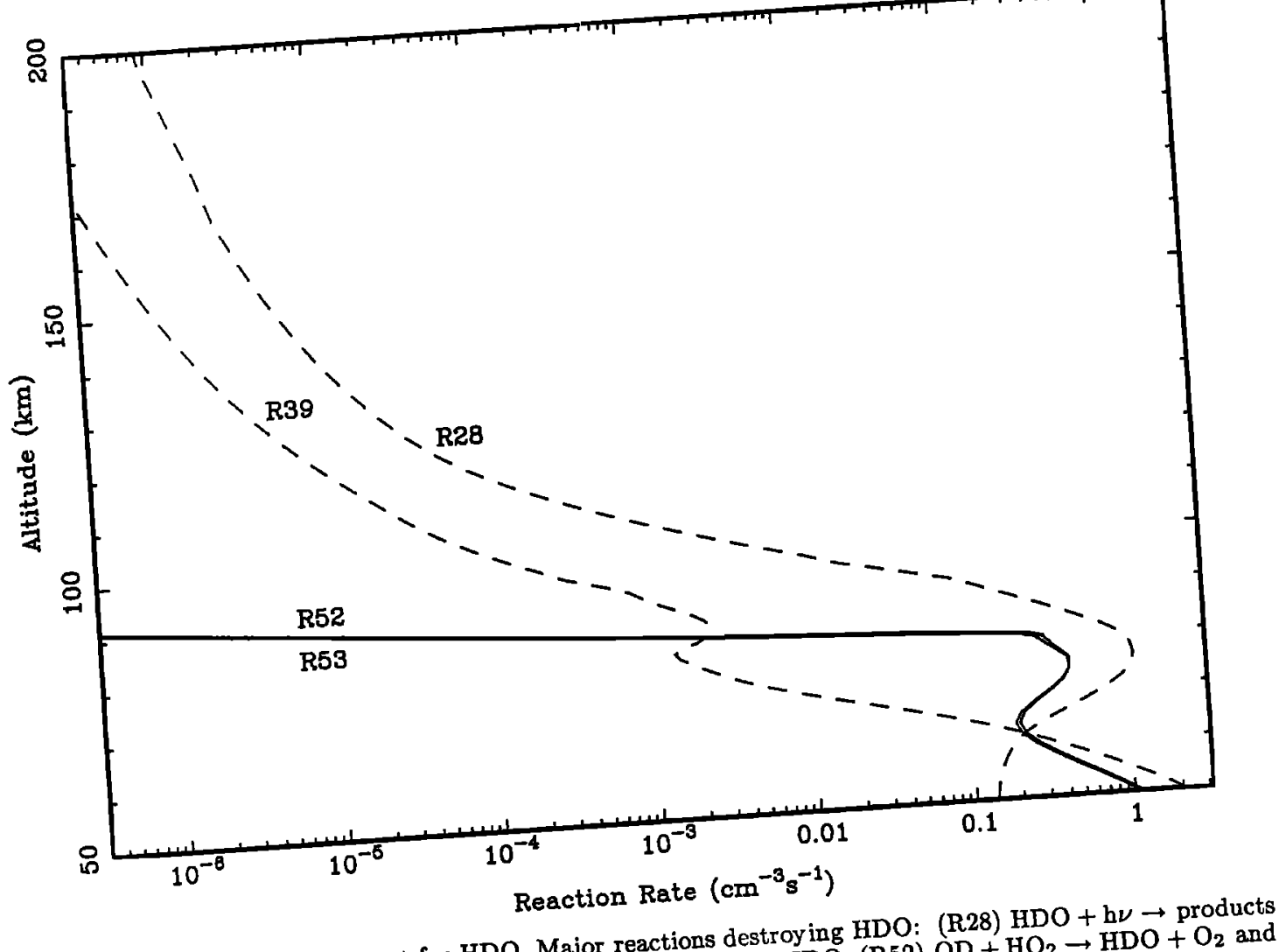

Fig. 8a. Same as Figure 5a, except for HDO. Major reactions destroy ing $\mathrm{HDO}: \stackrel{\mathrm{R2}}{\mathrm{O}}+\mathrm{HO}_{2} \rightarrow \mathrm{HDO}+\mathrm{O}_{2}$ and and (R39) $\mathrm{HDO}+\mathrm{O}\left({ }^{1} \mathrm{D}\right) \rightarrow \overrightarrow{\mathrm{PrO}}$

(R53) $\mathrm{OH}+\mathrm{DO}_{2} \rightarrow \mathrm{HDO}+\mathrm{O}_{2}$

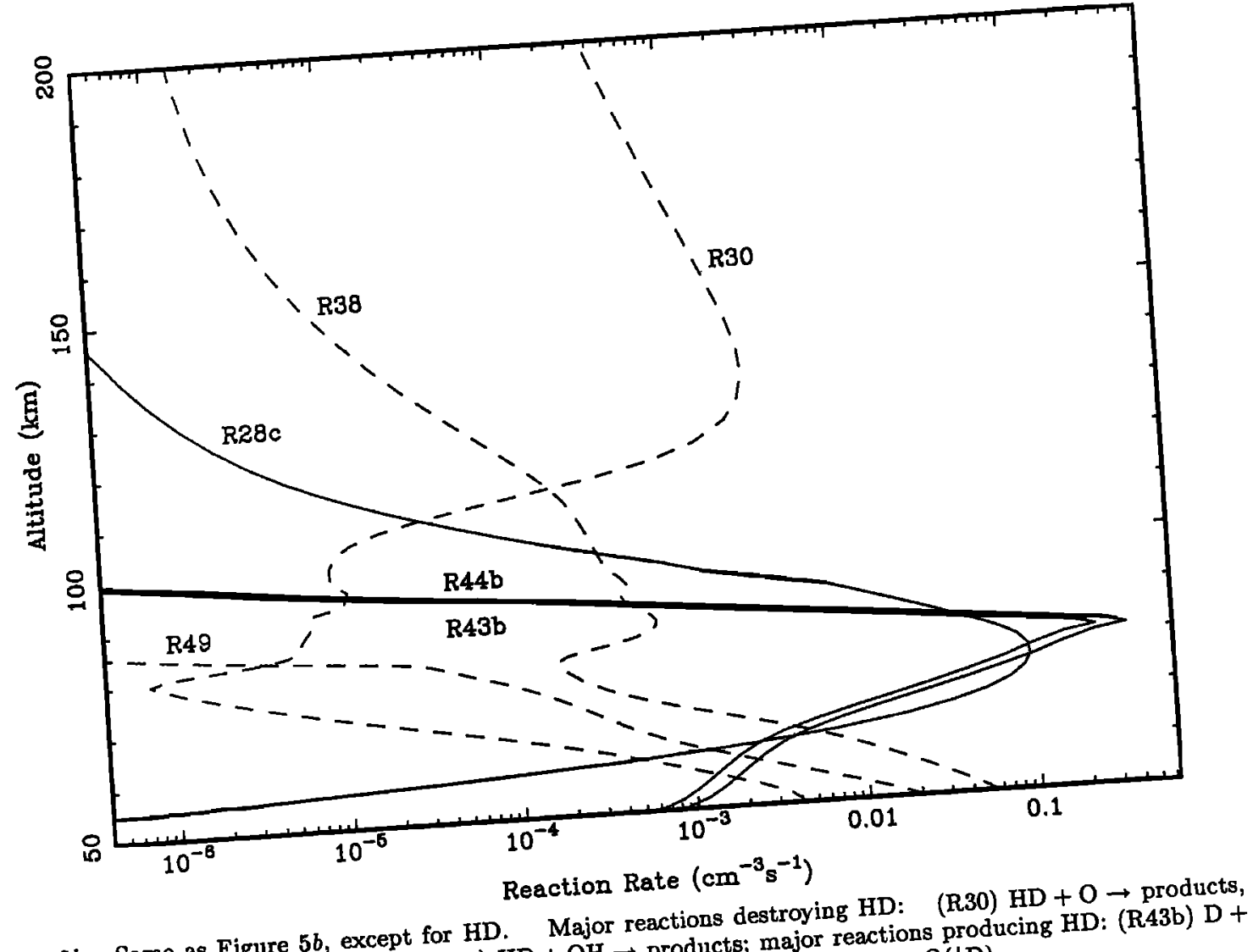

Fig. 8b. Same as Figure 5b, except for $\mathrm{HD}$. $\mathrm{HD}+\mathrm{OH} \rightarrow$ products; major reactions producin $+\mathrm{O}$ ( (R38) $\mathrm{HD}+\mathrm{O}(\mathrm{D})(\mathrm{R} 44 \mathrm{~b}) \mathrm{H}+\mathrm{DO}_{2} \rightarrow \mathrm{HD}+\mathrm{O}_{2}$, and (R28c) $\mathrm{HDO}+\mathrm{h} \nu \rightarrow \mathrm{HD}$ 


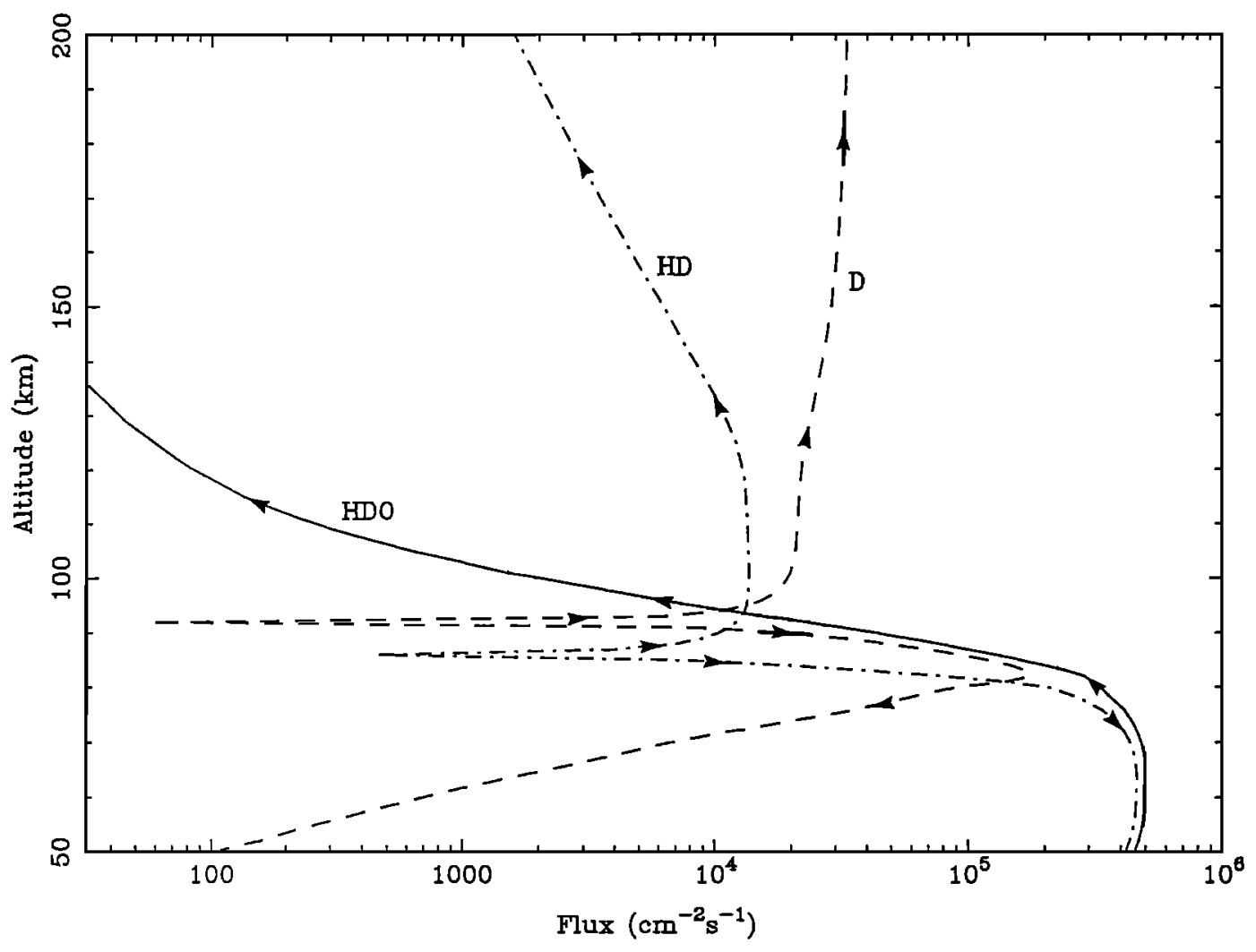

Fig. 9. Same as Figure 6, except for major deuterium species.

TABLE 3a. Comparison of Model and Observations of Breig et al. [1987]

\begin{tabular}{lcc}
\hline & Model & Observation \\
\hline Exospheric temperature, $\mathrm{K}$ & 926 & 930 \\
Exobase altitude, $\mathrm{km}$ & $\mathbf{4 3 2}$ & $\mathbf{4 0 2}$ \\
{$[\mathrm{O}]$ at exobase, $\mathrm{cm}^{-3}$} & $4.68 \times 10^{7}$ & $4.7 \times 10^{7}$ \\
{$[\mathrm{H}]$ at exobase, $\mathrm{cm}^{-3}$} & $1.89 \times 10^{5}$ & $1.9 \times 10^{5}$ \\
{$[\mathrm{D}]$ at exobase, $\mathrm{cm}^{-3}$} & $1.61 \times 10^{2}$ & $1.6 \times 10^{2}$ \\
\hline
\end{tabular}

are (1) Hunten's limiting flux is attained, and (2) almost $100 \%$ of the deuterium escape is due to nonthermal processes. The first result is new. The second has been anticipated by Kockarts [1972], although no quantitative flux computation was reported.

\section{NONTHERMAL ESCAPE}

In the previous section we found that about $76 \%$ of the hydrogen escape and $100 \%$ of the deuterium escape in our model must be explained by nonthermal escape processes. In this section we examine some of the previously studied nonthermal escape processes in order to determine whether these well-known processes can account for the magnitude of the nonthermal escape flux required by our model.

Various nonthermal escape mechanisms have been studied extensively in the past two decades, and good reviews of some of the earlier ideas are given by Chamberlain [1963], Tinsley [1974], and Hunten and Donahue [1976]. Detailed quantitative studies have been performed for the two most important terrestrial nonthermal hydrogen-escape mechanisms, charge exchange [e.g., Maher and Tinsley, 1977] and polar wind [e.g., Banks and Holzer, 1969]. These two mech- anisms are somewhat complementary processes: charge exchange works only at middle and low latitudes in regions with closed magnetic field lines, while polar wind loss takes place at high latitudes in regions with open magnetic field lines. Within their respective regions the polar wind process seems to be the more effective, but charge exchange dominates (at least for hydrogen escape) when the fluxes are averaged over the entire globe.

We have extended the previous charge-exchange model of Maher and Tinsley [1977] and polar wind model of Banks and Holzer [1969] to include the escape of deuterium as well as hydrogen. By estimating the relative efficiency at which $\mathrm{D}$ and $\mathrm{H}$ escape to space, we can compare the predicted nonthermal $H$ and $D$ escape flux (due to charge exchange and polar wind) with the nonthermal escape flux required by our photochemical model and so evaluate our current knowledge concerning nonthermal escape.

\section{Charge Exchange}

Hot ions in the plasmasphere are trapped in the Earth's magnetic field and cannot escape. However, they can exchange charge with atoms in the exosphere to create fast 


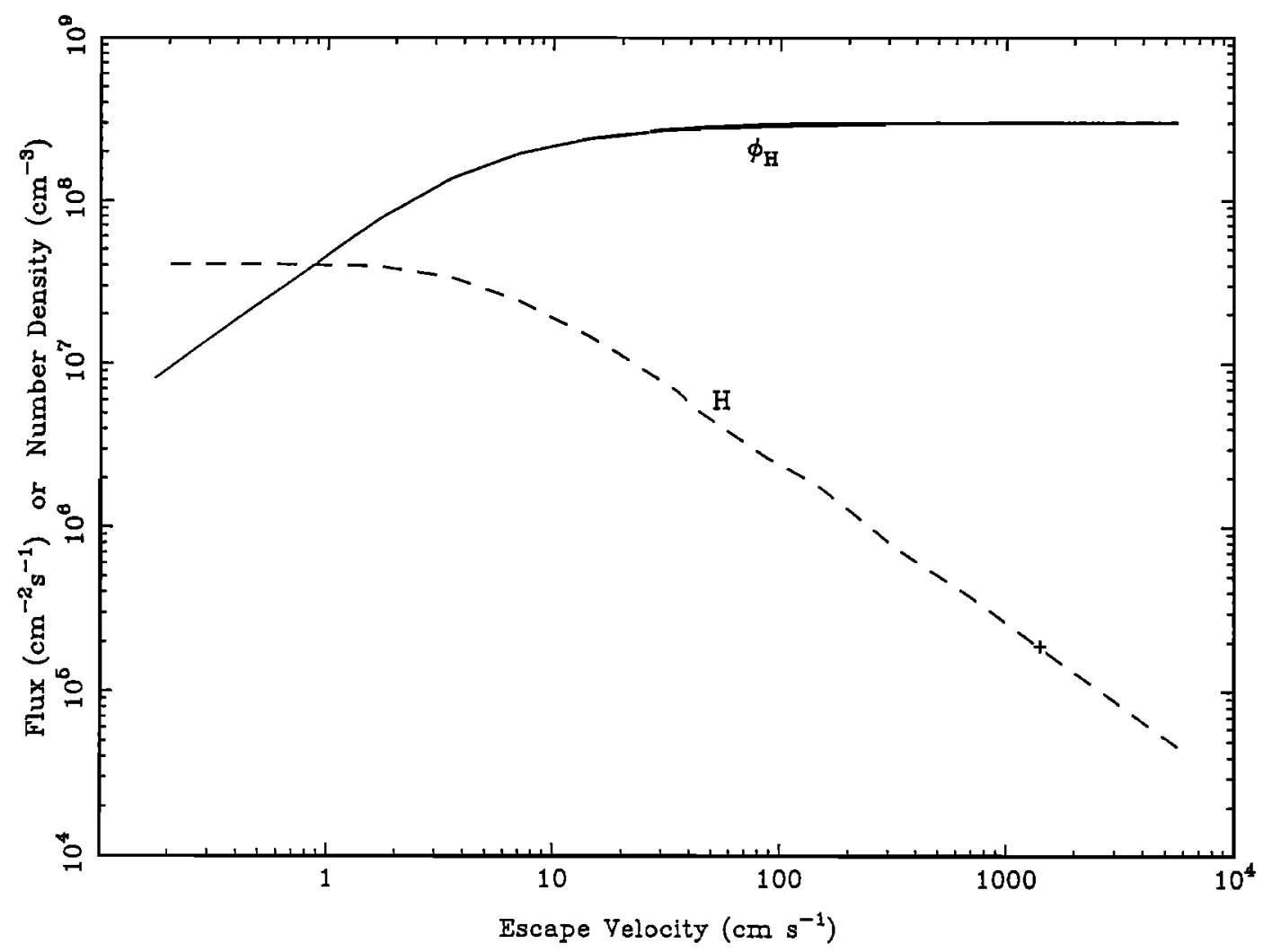

Fig. 10a. Escape flux of hydrogen and number density of hydrogen at the exobase, as a function of the effective escape velocity. The cross shows the value of $H$ deduced by Breig et al. [1987].

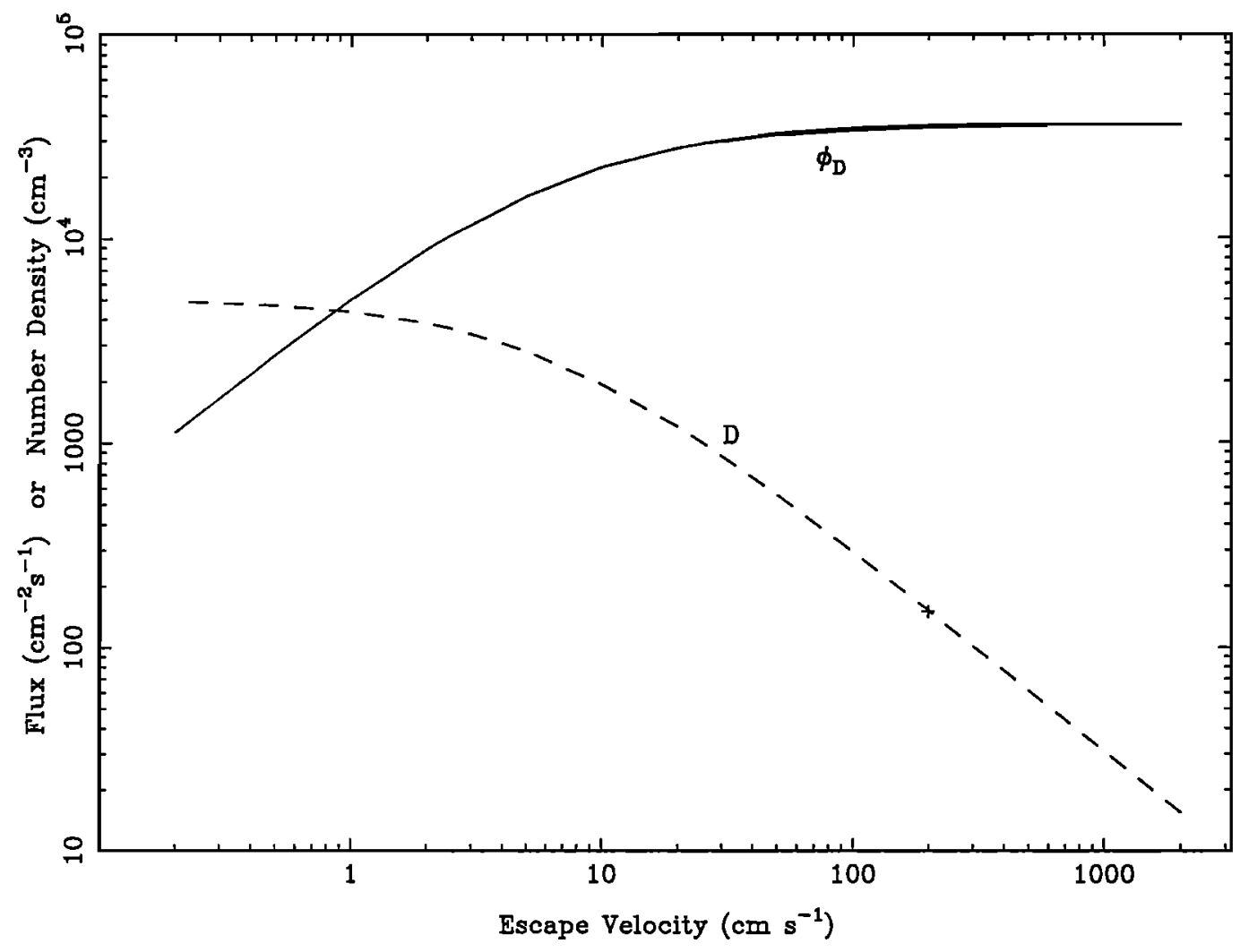

Fig. 10b. Same as Figure 10a, except for deuterium. 
TABLE $3 b$. Summary of Fluxes for H and D Computed by Our Model

\begin{tabular}{clccc}
\hline $\mathrm{i}$ & \multicolumn{1}{c}{ Type } & $\phi_{i}(\mathrm{H})$ & $\phi_{i}(\mathrm{D})$ & $R_{i}$ \\
\hline$(1)$ & total & $3.02 \times 10^{8}$ & $3.49 \times 10^{4}$ & 0.74 \\
$(2)$ & thermal & $7.14 \times 10^{7}$ & $3.9 \times 10^{1}$ & $3.5 \times 10^{-3}$ \\
$(3)$ & expected nonthermal & $2.31 \times 10^{8}$ & $3.49 \times 10^{4}$ & 0.97 \\
& $\phi_{1}-\phi_{2}$ & & & \\
$(4)$ & charge exchange & $1.41 \times 10^{8}$ & $5.38 \times 10^{3}$ & 0.24 \\
$(5)$ & polar wind & $4.6 \times 10^{7}$ & $1.5 \times 10^{4}$ & 2.1 \\
$(6)$ & computed nonthermal & $1.9 \times 10^{8}$ & $2.0 \times 10^{4}$ & 0.67 \\
& & & \\
\hline
\end{tabular}

Fluxes are given in atoms $\mathrm{cm}^{-2} \mathrm{~s}^{-1}$. The efficiency factor $R_{\imath}$ is defined by $R_{i}=\left(\phi_{\mathrm{i}}(\mathrm{D}) / \phi_{\mathrm{i}}(\mathrm{H})\right) /(\mathrm{D} / \mathrm{H})_{\mathrm{o}}$, where $(\mathrm{D} / \mathrm{H})_{0}$ refers to sea level.

neutral atoms. These neutral atoms can escape from the Earth if they have enough energy after the charge-exchange reaction and if they are pointed up rather than down toward the Earth. The charge-exchange mechanism only becomes important in the regions of the ionosphere above the exobase and is only important if ion temperatures are higher than the neutral temperatures.

Four reactions govern the charge-exchange loss of hydrogen and deuterium from the Earth (see Table 1c). These reactions proceed very rapidly and are temperature dependent. The fast neutral $\mathrm{H}$ and $\mathrm{D}$ atoms produced in these four reactions will have nearly the same average energy as the incident ions and will have velocities which follow a Maxwellian velocity distribution. Since the $1974 \mathrm{AE}-\mathrm{C}$ orbits [Maher and Tinsley, 1977] show ion temperatures $T_{i}$ ranging from 1000 to $6000 \mathrm{~K}$, the product neutrals will have average energies ranging from 0.09 to $0.52 \mathrm{eV}$. Those atoms with velocities in the tail of the Maxwellian velocity distri- bution with energies greater than $0.66 \mathrm{eV}$ for hydrogen or $1.3 \mathrm{eV}$ for deuterium can escape. The fraction of the atoms that will escape, $\alpha_{e s c}^{\mathrm{H}}$ and $\alpha_{e s c}^{\mathrm{D}}$, is determined in the following manner:

$$
\alpha_{e s c}^{j}=B\left[1-\frac{v_{e s c}^{2}}{u_{j}^{2}(z)}\right] \exp \left[-\frac{v_{e s c}^{2}}{u_{j}^{2}(z)}\right]
$$

where $B$ is the efficiency factor $=0.72$ for the Earth (see the section on thermal escape), the index $j=1,2$ for $\mathrm{H}$ and $\mathrm{D}$, respectively, $u_{j}$ is the most probable velocity,

$$
u_{j}=\sqrt{\frac{2 k T_{i}}{m_{\jmath}}}
$$

and $v_{e s c}$ is the escape velocity, $11.2 \mathrm{~km} \mathrm{~s}^{-1}$. Figure 11 shows the variation in $\alpha_{e s c}^{H}$ and $\alpha_{e s c}^{D}$ with height in the exosphere

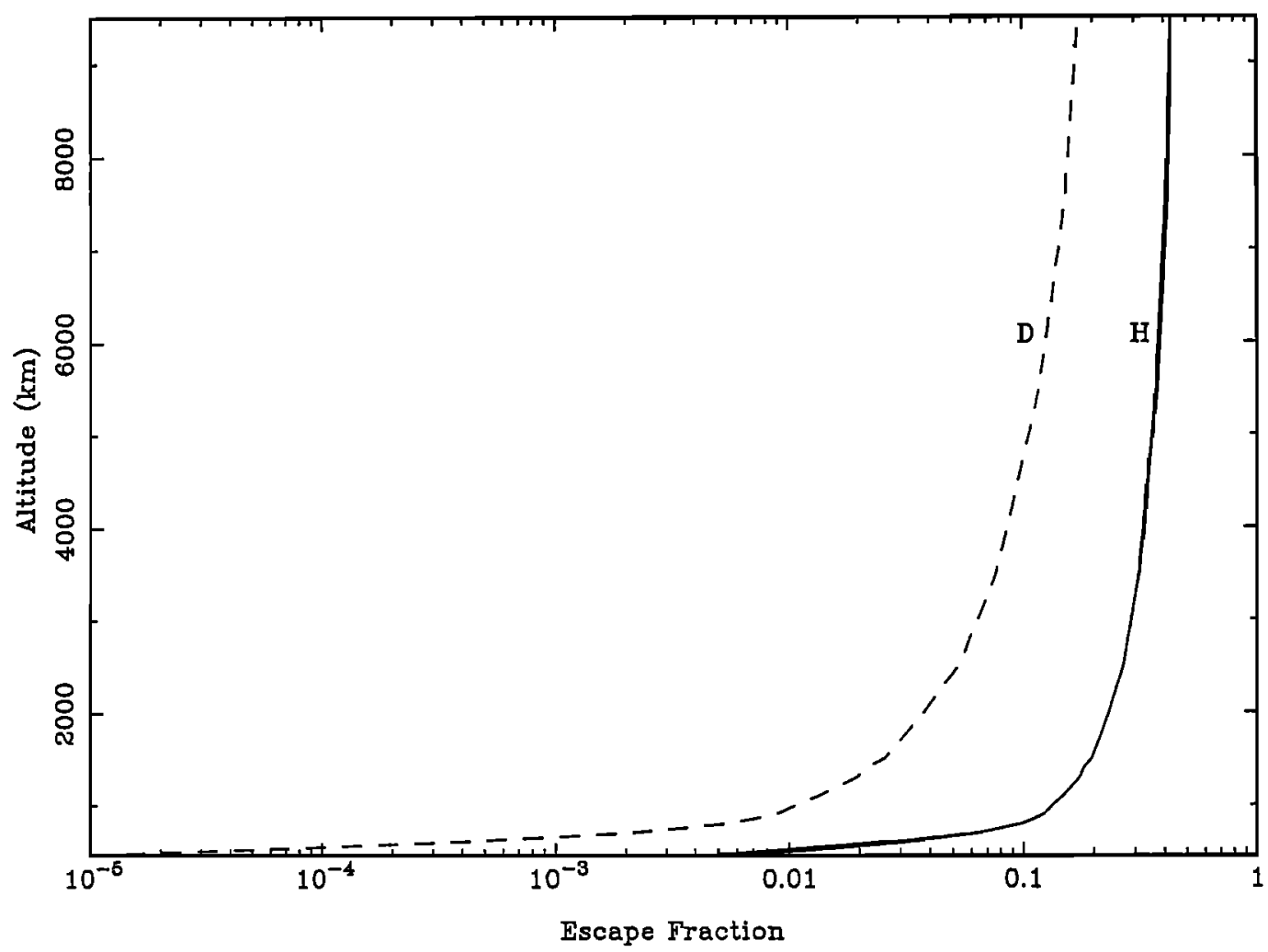

Fig. 11. Fraction deuterium (see text).

of the atoms that will escape from the exosphere: $a_{e s c}(\mathrm{H})$ for hydrogen, $a_{e s c}(\mathrm{D})$ for 
TABLE 1c. List of Essential Reactions for the Ionosphere With Their Preferred Rate Coefficients

\begin{tabular}{|c|c|c|c|}
\hline $\begin{array}{c}\text { Reaction } \\
\text { No. }\end{array}$ & Reaction & Rate Constant & Reference \\
\hline (R58) & $H_{\text {fast }}^{+}+H \rightarrow \mathrm{H}_{\text {fast }}+\mathrm{H}^{+}$ & $6.5 \times 10^{-11} \sqrt{T_{2}}$ & a \\
\hline (R59) & $\mathrm{H}_{\text {fast }}^{+}+\mathrm{O} \rightarrow \mathrm{H}_{\text {fast }}+\mathrm{O}^{+}$ & $0.80 k_{58}$ & $b$ \\
\hline (R60) & $\mathrm{D}_{\text {fast }}^{+}+\mathrm{H} \rightarrow \mathrm{D}_{\text {fast }}+\mathrm{H}^{+}$ & $0.87 k_{58}$ & b \\
\hline (R61) & $\mathrm{D}_{\text {fast }}^{+}+\mathrm{O} \rightarrow \mathrm{D}_{\text {fast }}+\mathrm{O}^{+}$ & $0.58 k_{58}$ & b \\
\hline (R62) & $\mathrm{O}^{+}+\mathrm{H} \rightarrow \mathrm{O}+\mathrm{H}^{+}$ & see text & \\
\hline (R63) & $\mathrm{H}^{+}+\mathrm{O} \rightarrow \mathrm{H}+\mathrm{O}^{+}$ & see text & \\
\hline (R64) & $\mathrm{O}^{+}+\mathrm{D} \rightarrow \mathrm{O}+\mathrm{D}^{+}$ & $0.73 k_{62}$ & b \\
\hline (R65) & $\mathrm{D}^{+}+\mathrm{O} \rightarrow \mathrm{D}+\mathrm{O}^{+}$ & $0.73 k_{63}$ & b \\
\hline
\end{tabular}

Reference citations are as follows: a, Newman et al. [1982]; b, estimated.

(when an ion temperature profile similar to Figure 1 of $\mathrm{Ma}$ her and Tinsley, [1977] is used). Note that $\alpha_{e s c}^{H}$ is several orders of magnitude larger than $\alpha_{e s c}^{D}$ in the lower part of the exosphere but is only a factor of 3 larger high up in the exosphere.

If we assume that the velocities of the neutral species $H$, $D$, and $\mathrm{O}$ in the thermosphere follow a Maxwell-Boltzmann distribution, then the equations for the charge-exchange escape flux of hydrogen and deuterium (see equation (4) of Maher and Tinsley [1977]) can be simplified to

$$
\begin{aligned}
& \phi_{4}(\mathrm{H})= \\
& \int_{z_{c}}^{z_{p p}}\left(\frac{R_{o}+z}{R_{o}}\right)^{2} a_{e s c}^{\mathrm{H}}\left(k_{58}\left[\mathrm{H}^{+}\right][\mathrm{H}]+k_{59}\left[\mathrm{H}^{+}\right][\mathrm{O}]\right) d z \\
& \phi_{4}(\mathrm{D})= \\
& \int_{z_{c}}^{z_{p p}}\left(\frac{R_{o}+z}{R_{o}}\right)^{2} a_{e s c}^{\mathrm{D}}\left(k_{60}\left[\mathrm{D}^{+}\right][\mathrm{H}]+k_{61}\left[\mathrm{D}^{+}\right][\mathrm{O}]\right) d z
\end{aligned}
$$

where $a_{e s c}^{H}$ and $a_{e s c}^{D}$ are the escape fractions of $\mathrm{H}$ and D, $k$ is the rate coefficient of the relevant reaction, $\left[\mathrm{H}^{+}\right],\left[\mathrm{D}^{+}\right]$, $[\mathrm{H}],[\mathrm{D}]$, and $[\mathrm{O}]$ are the number densities of the relevant species, and the integral is evaluated from the exobase $\left(z_{c}\right)$ to the plasmapause $\left(z_{p p}\right), R_{o}$ is the radius of the Earth, and $\left(R_{o}+z\right)^{2} / R_{o}^{2}$ normalizes the flux to the Earth's surface.

The first charge-exchange reaction listed in Table $1 c$ (R58) is the only reaction that has been studied in the laboratory [Newman et al., 1982], but the other rate coefficients can be calibrated from this reaction by considering theoretical studies of charge-exchange reactions. Such studies show that the rate coefficient $k$ is proportional to $(\alpha / \mu)^{1 / 2}$, where $\alpha$ is the polarizability of the neutral species and $\mu=m_{i} m_{n} /\left(m_{i}+m_{n}\right)$ is the reduced mass of the ion-neutral system [cf. Bauer, 1973]. The polarizability of atomic oxygen is $8.02 \times 10^{-25} \mathrm{~cm}^{3}$ and of atomic hydrogen is $6.67 \times 10^{-25} \mathrm{~cm}^{3}$ [Miller and Bederson, 1977]. The values for the rate coefficients $\left(k_{58}-k_{61}\right)$, adopted in our computation are summarized in Taple $1 c$.

Maher and Tinsley [1977] used data on ion and electron temperatures and concentrations obtained by the Atmosphere Explorer $\mathrm{C}$ and Arecibo to calculate the hydrogen escape flux from the Eàrth. They found escape fluxes (normalized to the Earth's surface) that range from $6 \times 10^{7}$ to $7 \times 10^{8} \mathrm{~cm}^{-2} \mathrm{~s}^{-1}$, depending on latitude and time.

We perform a similar calculation for hydrogen and deuterium, using data from Breig et al. [1987] for a late afternoon (16 hours), mid-latitude $\left(22^{\circ} \mathrm{S}\right)$, winter orbit of the AE-C. The concentrations of the neutral species $H, D$, and
$O$ are calculated assuming diffusive equilibrium with a thermospheric temperature of $930 \mathrm{~K}$. Neutral concentrations of $[\mathrm{H}]=1.9 \times 10^{5},[\mathrm{D}]=1.5 \times 10^{2}$, and $[\mathrm{O}]=2.2 \times 10^{7} \mathrm{~cm}^{-3}$ at $450 \mathrm{~km}$ are chosen to match observations from the $A E-$ C satellite [Breig et al., 1987], and the ion concentration profiles $\left(\left[\mathrm{H}^{+}\right]\right.$and $\left.\left[\mathrm{D}^{+}\right]\right)$are determined by assuming diffusive equillibrium with an ion temperature profile similar to Figure 1 of Maher and Tinsley [1977] (temperatures ranging from $1200 \mathrm{~K}$ at $500 \mathrm{~km}$ to $5500 \mathrm{~K}$ at $9500 \mathrm{~km}$ ). The plasmapause height $z_{p p}$ is chosen to be $9500 \mathrm{~km}$. Figure 12 shows the exospheric concentrations used in this charge-exchange study.

Figure 13 shows our calculated charge-exchange escape rate as a function of altitude. We find an escape flux for hydrogen $\phi_{4}(\mathrm{H})=1.41 \times 10^{8} \mathrm{~cm}^{-2} \mathrm{~s}^{-1}$, and for deuterium $\phi_{4}(\mathrm{D})=5.38 \times 10^{3} \mathrm{~cm}^{-2} \mathrm{~s}^{-1}$. The hydrogen escape value falls within the limits stated by Maher and Tinsley [1977] for the $1974 \mathrm{AE}-\mathrm{C}$ orbits. This result is somewhat fortuitous, however. We used slightly different rate coefficients and density profiles than Maher and Tinsley. Our $\mathrm{H}^{+}$densities were lower for the most part, causing our calculation to be lower than theirs; on the other hand, our $\mathrm{H}^{+}+\mathrm{O}$ reaction rate was higher, causing our oxygen charge-exchange reaction to be more important than Maher and Tinsley realized and elevating our escape rate. In addition, Maher and Tinsley's values were normalized to $500 \mathrm{~km}$, while ours were normalized to the surface.

\section{Polar Wind}

Protons and other ions cannot normally escape from the Earth's upper atmosphere because they are trapped by the magnetic field. At large magnetic latitudes, however, the field lines are open to the tail of the magnetosphere, and ions can rapidly escape along these field lines, in effect, creating a "polar wind" of escaping ions. Neutral hydrogen and deuterium in the upper atmosphere can be ionized by charge-exhange reactions and so can escape from the Earth at high magnetic latitudes.

The production of $\mathrm{H}^{+}$in the ionosphere is controlled by the charge-exchange reactions (R62) and (R63) (Table 1c). The integral form of the continuity equation implies that the polar wind escape flux is

$$
\begin{aligned}
\phi_{p w}(\mathrm{H}) & =\int_{z_{1}}^{z_{2}}\left(\frac{R_{o}+z}{R_{o}}\right)^{2} k_{62}[\mathrm{H}]\left[\mathrm{O}^{+}\right] d z \\
& -\int_{z_{1}}^{z_{2}}\left(\frac{R_{o}+z}{R_{o}}\right)^{2} k_{63}\left[\mathrm{H}^{+}\right][\mathrm{O}] d z
\end{aligned}
$$




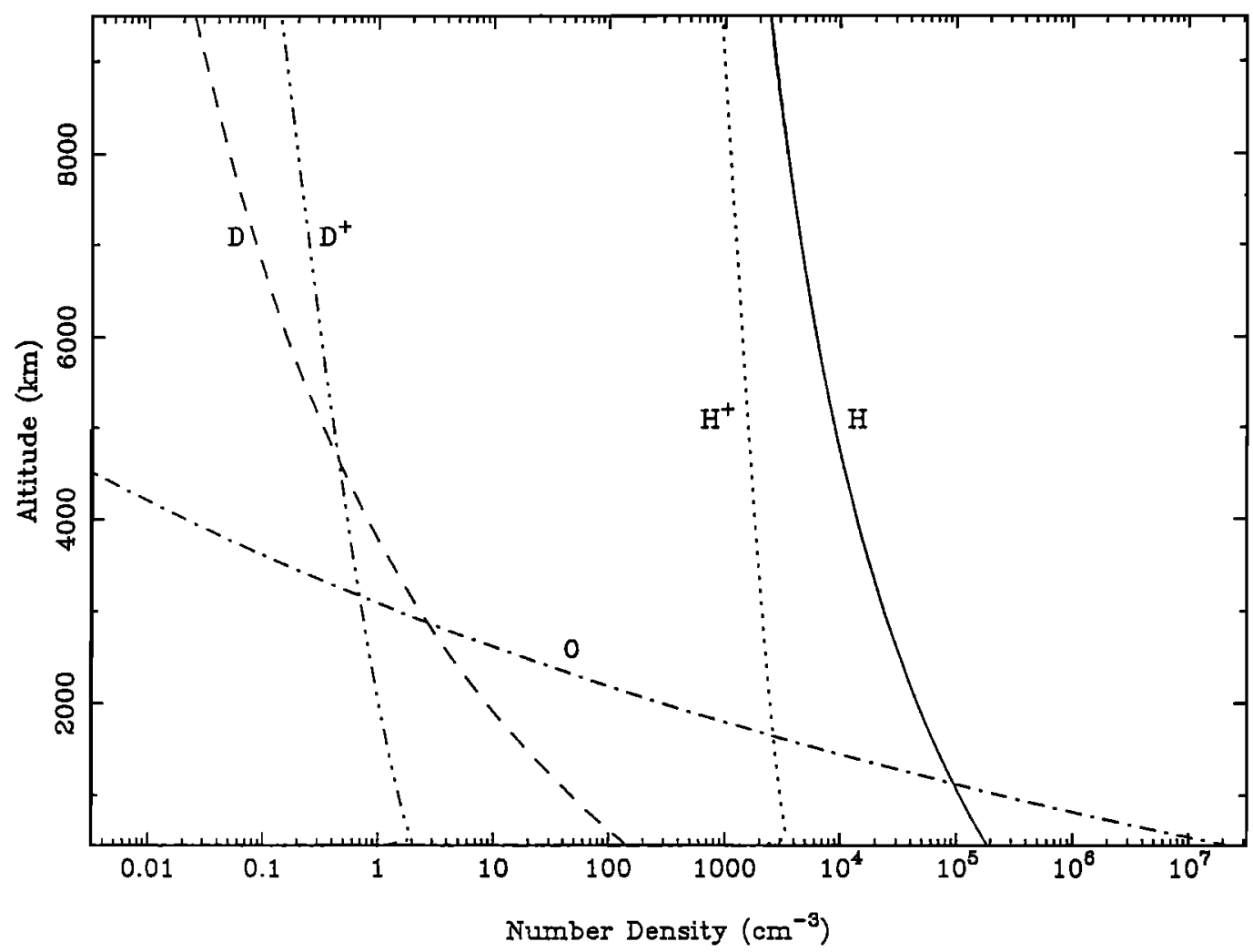

Fig. 12. Concentrations of important atomic and ionic species in the exosphere model.

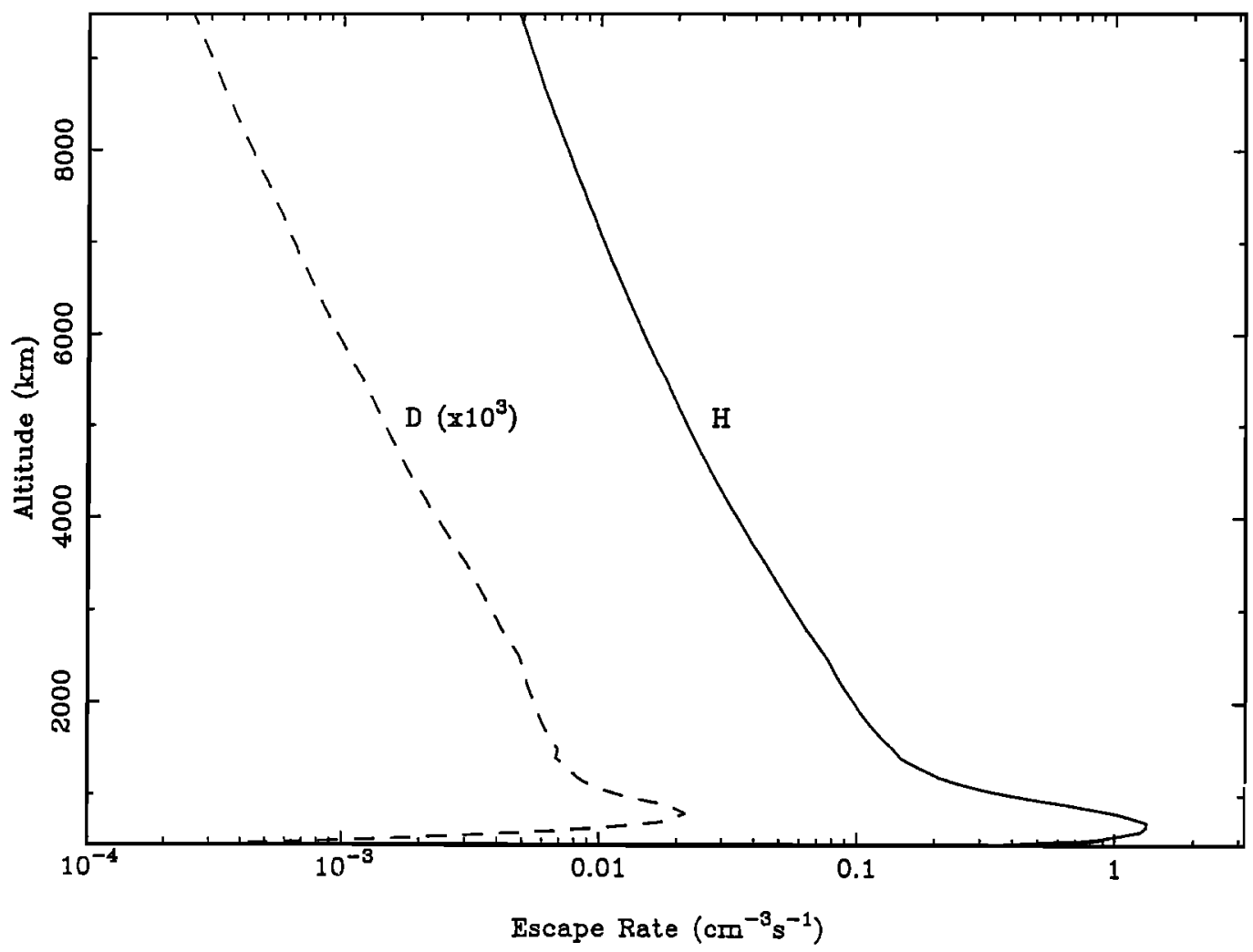

Fig. 13. Escape rates (integrand of the flux integral) for charge exchange in the exosphere. 
where $k_{62}$ and $k_{63}$ are the forward and reverse reaction rate coefficients of the charge-transfer equation, and the integral is evaluated throughout the ionosphere from about $z_{1} \sim 250$ $\mathrm{km}$ to $z_{2} \sim 3000 \mathrm{~km}$ [Liu and Donahue, 1974b].

The deuterium escape due to the polar wind mechanism is similar to that of the hydrogen escape. The key reactions are (R64) and (R65). Therefore the escape rate of $\mathrm{D}^{+}$is given by

$$
\begin{aligned}
\phi_{p w}(\mathrm{D}) & =\int_{z_{1}}^{z_{2}}\left(\frac{R_{o}+z}{R_{o}}\right)^{2} k_{64}[\mathrm{D}]\left[\mathrm{O}^{+}\right] d z \\
& -\int_{z_{1}}^{z_{2}}\left(\frac{R_{o}+z}{R_{o}}\right)^{2} k_{65}\left[\mathrm{D}^{+}\right][\mathrm{O}] d z
\end{aligned}
$$

with $k_{64}$ and $k_{65}$ being the forward and reverse reaction rate coefficients. The integrals are evaluated over the same limits as in the $\mathrm{H}^{+}$escape problem. The concentrations of $\mathrm{H}^{+}, \mathrm{D}^{+}$, and $\mathrm{O}^{+}$are strongly affected by the outward flow of ionospheric plasma, so a simple evaluation of these integrals is not possible. Banks and Holzer [1969] have studied the high-latitude transport of $\mathrm{H}^{+}$and $\mathrm{He}^{+}$in detail, using corrected ion concentrations. We will use their results to estimate the effect of polar wind flow of $\mathrm{H}^{+}$on the neutral hydrogen in the rest of the atmosphere. In addition, we will use their results to estimate the high latitude $\mathrm{D}^{+}$flow relative to the $\mathrm{H}^{+}$flow.

Since the polarizabilities of $\mathrm{H}$ and $\mathrm{D}$ are nearly identical and since the reaction rates are proportional to $\mu^{-1 / 2}$, then $k_{64}=0.73 k_{62}$ and $k_{65}=0.73 k_{63}$. If we also assume that $[\mathrm{D}] /[\mathrm{H}] \approx\left[\mathrm{D}^{+}\right] /\left[\mathrm{H}^{+}\right]$in the altitude region from 250 to $3000 \mathrm{~km}$ then, roughly,

$$
\frac{\phi_{p w}(\mathrm{D})}{\phi_{p w}(\mathrm{H})} \approx 0.73 \overline{\left(\frac{[\mathrm{D}]}{[\mathrm{H}]}\right)}
$$

where $\overline{([\mathrm{D}] /[\mathrm{H}])}$ is the mean $\mathrm{D} / \mathrm{H}$ ratio above the exobase (about $4.4 \times 10^{-4}$ according to data presented by Breig et al., [1987] and to our own exospheric model, as shown in Figure 12).

The depletion of $\mathrm{H}^{+}$and $\mathrm{D}^{+}$in the polar region will create a lateral flow of neutral $\mathrm{H}$ and $\mathrm{D}$ from equator and midlatitude regions to the poles needed to supply the outgoing ion flux [Banks and Holzer, 1969]. Using detailed calculations of the polar wind flow and its effect on ion concentrations in the polar regions, Banks and Holzer find an $\mathrm{H}^{+}$ escape flux of $\phi_{p w}(\mathrm{H})=5.7 \times 10^{8} \mathrm{~cm}^{-2} \mathrm{~s}^{-1}$ for a neutral exospheric temperature of $1000 \mathrm{~K}$ and an ion temperature of $2750 \mathrm{~K}$, normalized to $1000 \mathrm{~km}$. We follow the method of Liu and Donahue [1974b] in crudely estimating the effect of this polar wind flow on the rest of the globe by assuming that the polar wind flow is constrained to two spherical caps each $20^{\circ}$ in width (a total of $6 \%$ of the total surface area of the sphere). If we assume that the outgoing ion flux is supplied uniformly by lateral flow from the nonpolar latitudes, then a global average of $6 \%$ times $5.7 \times 10^{8}$ times 1.34 to normalize to the Earth's surface or $\phi_{5}(\mathrm{H})=4.6 \times 10^{7} \mathrm{H}$ atoms $\mathrm{cm}^{-2} \mathrm{~s}^{-1}$ will escape due to polar wind flow. We can find the global average of polar-wind-induced deuterium escape by appropriately scaling the hydrogen escape flux found by Banks and Holzer [1969]. In other words,

$$
\begin{aligned}
\phi_{5}(\mathrm{D}) & =\phi_{p w}(\mathrm{H}) \overline{\left(\frac{[\mathrm{D}]}{[\mathrm{H}]}\right)}(0.73)(6 \%)(1.34) \\
& =1.5 \times 10^{4} \mathrm{~cm}^{-2} \mathrm{~s}^{-1}
\end{aligned}
$$

( $\phi_{5}$ is the globally averaged polar wind escape flux referred to the surface). Therefore the total nonthermal escape flux due to both the polar wind and charge-exchange mechanisms is

$$
\begin{aligned}
& \phi_{6}(\mathrm{H})=\phi_{4}(\mathrm{H})+\phi_{5}(\mathrm{H})=1.9 \times 10^{8} \mathrm{~cm}^{-2} \mathrm{~s}^{-1} \\
& \phi_{6}(\mathrm{D})=\phi_{4}(\mathrm{D})+\phi_{5}(\mathrm{D})=2.0 \times 10^{4} \mathrm{~cm}^{-2} \mathrm{~s}^{-1}
\end{aligned}
$$

compared with the expected nonthermal fluxes of $\phi_{3}(\mathrm{H})=$ $2.3 \times 10^{8}$ and $\phi_{3}(\mathrm{D})=3.5 \times 10^{4} \mathrm{~cm}^{-2} \mathrm{~s}^{-1}$.

These results show that the charge-exchange and polar wind mechanisms do not seem to account for the total required nonthermal escape flux (see Table $3 b$ ). The two mechanisms together account for about $83 \%$ of the nonthermal hydrogen flux and only about $57 \%$ of the nonthermal deuterium flux. The discrepancy between the total required nonthermal flux and the flux provided by charge exchange and polar wind may be a real discrepancy or may just represent the uncertainty in our calculations. Small changes in magnetic parameters or solar insolation may have a big impact on the charge-exchange and polar wind escape fluxes and prevent exact calculations from being feasible. In addition, our modeling of the lateral flow created by the polar wind mechanism was rather crude; a more detailed calculation will be necessary before a firm conclusion concerning the discrepancy can be reached. If we arbitrarily double the polar wind escape flux, then we have $\phi_{4}(\mathrm{H})+2 \phi_{5}(\mathrm{H})=2.4 \times 10^{8}$ and $\phi_{4}(\mathrm{D})+2 \phi_{5}(\mathrm{D})=3.5 \times 10^{4}$ $\mathrm{cm}^{-2} \mathrm{~s}^{-1}$. These results are in almost perfect agreement with the expected nonthermal fluxes $\phi_{3}(\mathrm{H})$ and $\phi_{3}(\mathrm{D})$. On the other hand, some unknown nonthermal escape process or one that has previously been considered insignificant may be important for escape of hydrogen and deuterium under the specific atmospheric conditions considered here.

\section{Discussion}

We will now briefly discuss the insight we have gained about the mechanisms of the escape of $\mathrm{H}$ and $\mathrm{D}$ from the terrestrial atmopshere and the implications for atmospheric evolution. At solar minimum, for which our model is appropriate, the escape of hydrogen is dominated by charge exchange with somewhat less contribution from thermal evaporation. Polar wind accounts for less than $20 \%$ of the total escape flux (see Table $3 b$ for details). The charge exchange mechanism is in principle similar to the thermal mechanism. The main difference lies in the sources of the energetic particles: hot ions versus hot neutrals in the respective tails of Maxwellian distributions. Since the ion temperature is much higher than the neutral temperature, this explains the higher efficiency of escape by charge transfer. At solar maximum the neutral temperature can exceed $1500 \mathrm{~K}$ and thermal escape may become more important than charge exchange. Polar wind escape is relatively insensitive to either the ion or neutral temperature.

The escape of $D$ can best be understood by comparison with that of $\mathrm{H}$. Let us define an efficiency factor for the escape of $D$ relative to $H$, 


$$
R_{i}=\frac{\phi_{i}(\mathrm{D}) / \phi_{i}(\mathrm{H})}{(\mathrm{D} / \mathrm{H})_{\circ}}
$$

where $\phi_{i}(\mathrm{H})$ and $\phi_{\imath}(\mathrm{D})$ are summarized in Table $3 b$, and $(\mathrm{D} / \mathrm{H})_{0}$ refers to sea level. The efficiency factor for total escape is $R_{1}=0.74$. This is primarily a consequence of Hunten's limiting flux theorem, and the primary factor contributing to this value is the lower molecular diffusion coefficient of $D$ relative to $H$. Thermal escape of $D$ is negligible because of its higher mass. Escape by charge exchange is also inefficient for the same reason. Hence polar wind becomes the dominant mechanism, accounting for $75 \%$ of the computed nonthermal flux. Since polar wind operates only in the polar regions of the planetary exosphere, this is not a very efficient process. This is the primary reason for the observed exospheric $\mathrm{D} / \mathrm{H}$ ratio enhancement by about a factor of 5 relative to $(\mathrm{D} / \mathrm{H})_{o}$.

The escape of hydrogen at a constant rate given by $\phi_{1}(\mathrm{H})$ could produce 0.5 bar of $\mathrm{O}_{2}$ over the age of the planet. This source is, however, insignificant compared with the biospheric source [Walker, 1977]. If we also assume a constant value for $R_{1}$, the preferential escape of $H$ over $\mathrm{D}$ would result in a higher $\mathrm{D} / \mathrm{H}$ ratio for seawater, $\delta D=2 \%$. This uniformitarian view may be too conservative. The $\mathrm{D} / \mathrm{H}$ ratio in deep-sea tholeiite glass containing primordial $\mathrm{He}$ and $\mathrm{Ne}$ was measured by Craig and Lupton [1976] to be $77 \%$ lower than the ratio in present seawater $\left(\mathrm{D} / \mathrm{H}=1.56 \times 10^{-4}\right)$. If we take this value to be the $\mathrm{D} / \mathrm{H}$ ratio of primordial water, the subsequent increase of the $\mathrm{D} / \mathrm{H}$ ratio must be accounted for. Using the same analysis as that described in a recent paper on the evolution of $\mathrm{H}$ and $\mathrm{D}$ in the Martian atmosphere [Yung et al., 1988] and assuming a constant $R_{1}=0.74$, we compute the ratio of the initial ocean to the present ocean masses to be 1.36. This implies that the escape of an amount of $\mathrm{H}_{2} \mathrm{O}$ equivalent to $36 \%$ of the present ocean has occurred in the past. A lower limit of the amount of $\mathrm{H}_{2} \mathrm{O}$ lost may be estimated by assuming that $R_{1}=0$; that is, deuterium did not escape. In this case, the amount of lost $\mathrm{H}_{2} \mathrm{O}$ is equivalent to $8.3 \%$ of the present ocean. The mean $\phi_{1}(\mathrm{H})$ averaged over geologic time is $1.3-5.8 \times 10^{10} \mathrm{~cm}^{-2} \mathrm{~s}^{-1}$ or about 50 200 times the present $\phi_{1}(\mathrm{H})$. Although this flux is much higher than the present flux, it is within the limits of the input flux of hydrogen to the early atmosphere, $1.9 \times 10^{9}$ to $1.9 \times 10^{13} \mathrm{~cm}^{-2} \mathrm{~s}^{-1}$ estimated by Holland [1984]. To account for such large fluxes we may have to invoke hydrodynamic escape early in the Earth's history [e.g., Zahnle and Kasting, 1986; Hunten et al., 1987; Zahnle et al., 1988]. It is not clear that our analysis is correct for such a large flux. Hence these results must be regarded as highly speculative. There may be an ambiguity in interpreting the data of Craig and Lupton [1976]. The authors mentioned that part of the $\mathrm{D} / \mathrm{H}$ fractionation might have taken place during outgassing as the water separated from the melt. Hence the fractionation that may be attributed to escape could be much less.

\section{CONCLUSIONS}

Accurate measurements of $\mathrm{D}$ and $\mathrm{H}$ in the thermosphere, combined with detailed photochemical modeling, provide stringent constraints on the role of thermal and nonthermal escape mechanisms for the loss of light species from the Earth's atmosphere. On the basis of the recent data of Breig et al. [1987] and our modeling studies, we conclude that pre- vious results obtained by Hunten and Strobel [1974] and Liu and Donahue $[1974 a, b, c]$ concerning thermal and nonthermal escape processes are generally correct. However, our modeling of $\mathrm{D}$ provides an extension of previous modeling and a more quantitative assessment of the relative importance of nonthermal mechanisms. Polar wind and charge exchange are both important nonthermal escape mechanisms. Polar wind is more important than charge exchange for deuterium escape, while charge exchange is more important for hydrogen escape. The two processes alone do not account for the full required nonthermal escape flux. This discrepancy may be due to the limits in our calculations of the charge-exchange and polar wind fluxes or may indicate that other nonthermal escape fluxes are important for the escape of $\mathrm{H}$ and $\mathrm{D}$ from the Earth. Our work has demonstrated the importance of the simultaneous measurement of total hydrogen (and deuterium) and crucial ions such as $\mathrm{O}^{+}, \mathrm{H}^{+}$, and $\mathrm{D}^{+}$. If the measurements are carried out at solar maximum as well as solar minimum, this may provide crucial tests of our model.

If the efficiency factor for the escape of $D$ relative to $H$ had remained constant in the past, a straightforward interpretation of the $\mathrm{D} / \mathrm{H}$ measurement in deep-sea tholeiite glass would imply that as much water as $36 \%$ of the present ocean might have been lost by the escape of hydrogen.

Acknowledgments: We thank D. Hunten and W. B. Hanson for illuminating discussions. This research was supported by NASA grant NAGW-1538 to the California Institute of Technology. Contribution number $\mathbf{4 5 7 5}$ from the Division of Geological and Planetary Sciences, California Institute of Technology, Pasadena, California.

\section{REFERENCES}

Ackerman, M., Ultraviolet solar radiation related to mesospheric processes, in Mesospheric Models and Related Eaperments, edited by G. Fiocco, pp. 149-159, Springer-Verlag, New York, 1971.

Allen, M., Y. L. Yung, and J. W. Waters, Vertical transport and photochemistry in the terrestrial mesosphere and lower thermosphere (50-120 km), J. Geophys. Res., 86, 3617-3627, 1981.

Allen, M., J. I. Lunine, and Y. L. Yung, The vertical distribution of ozone in the mesosphere and lower thermosphere, $J$. Geophys. Res., 89, 4841-4872, 1984.

Banks, P. M., and T. E. Holzer, High-latitude plasma transport: The polar wind, J. Geophys. Res., $\gamma_{4}, 6317-6332,1969$.

Bates, D. R., Some problems concerning the terrestrial atmosphere above about the $100 \mathrm{~km}$ level, Proc R. Soc. London, Ser. $A$, 253, 451-462, 1959.

Bauer, S. J., Physics of Planetary Ionospheres, Springer-Verlag, New York, 1973.

Berkner, L. V., and L. C. Marshall, On the origin and rise of oxygen concentration in the Earth's atmosphere, J. Atmos. Scr., 22, 225-261, 1965.

Bertaux, J. L., Observed variations of the exospheric hydrogen density with the exospheric temperature, J. Geophys. Res., 80, $639-642,1975$.

Breig, E. L., S. Sanatani, and W. B. Hanson, Deuterium in the daytime thermosphere, J. Geophys. Res., 92, 225-238, 1987.

Carver, J. H., H. P. Gies, T. I. Hobbs, B. R. Lewis, and D. G. McCoy, Temperature dependence of the molecular oxygen photoabsorption cross section near the H Lyman $\alpha$ line, J. Geophys. Res., 82, 1955-1960, 1977.

Chamberlain, J. W., Planetary coronae and atmospheric evaporation, Planet. Space Sci., 11, 901-960, 1963.

Chamberlain, J. W., and D. M. Hunten, Theory of Planetary Atmospheres, 2nd ed., Academic, San Diego, Calif., 1987.

Chamberlain, J. W., and G. R. Smith, Comments on the rate of evaporation of a non-Maxwellian atmosphere, Planet. Space Scz., $19,675-684,1971$. 
Climate Impact Assessment Program, The Natural Stratosphere of 1974, CIAP Monograph 1, pp. 5-184, Washington, D.C., 1975.

Cole, K. D., Theory of some quiet magnetospheric phenomena related to the geomagnetic tail, Nature, 211, 1385-1387, 1966.

Craig, H., Standard for reporting concentrations of deuterium and oxygen-18 in natural waters, Science, 199, 1833-1834, 1961.

Craig, H., and J. E. Lupton, Primordial neon, helium and hydrogen in oceanic basalts, Earth Planet. Sci. Lett., 31, 369-385, 1976.

DeMore, W. B., J. J. Margitan, M. J. Molina, R. T. Watson, D. M. Golden, R. F. Hampson, M. J. Kurylo, C. J. Howard and A. R. Ravishankara, Chemical Kinetics and Photochemical Data for use in Stratospheric Modeling, Evaluation 7, JPL Publ., 85-37, 1985.

DeMore, W. B., M. J. Molina, S. P. Sander, D. M. Golden, R. F. Hampson, M. J. Kurylo, C. J. Howard, and A. R. Ravishankara, Chemical Kinetics and Photochemical Data for use in Stratospheric Modeling, Evaluation 8, JPL Publ., 87-41, 1987.

Farmer, C. B., O. F. Raper, and F. G. O'Callaghan, Final Report on the First Flight of the ATMOS Instrument During the Spacelab 3 Mission, April 29 through May 6, 1985, JPL Publ., 87-32, 1987.

Garrett, B. C., D. G. Truhlar, J. M. Bowman, A. F. Wagner, D. Robie, S. Arepalli, N. Presser, and R. J. Gordon, Ab initio predictions and experimental confirmation of large tunneling contributions to rate constants and kinetic isotope effects for hydrogen atom transfer reactions, J. Am. Chem. Soc., 108, 3515-3516, 1986.

Haddad, G. N., and J. A. R. Samson, Total absorption and photoionization cross sections of water vapor between $100-1000 \AA$ J. Chem. Phys., 84, 6623-6626, 1986.

Hampson, R. F., Chemical Kinetics and Photochemical Data Sheets for Atmospheric Reactions, FAA-EE-80-17, U.S. Dep. of Transp., Washington, D. C., 1980.

Herman, J. R., and J. E. Mentall, $\mathrm{O}_{2}$ absorption cross section $(187-225 \mathrm{~nm})$ from stratospheric solar flux measurements, $J$. Geophys. Res., 87, 8967-8975, 1982.

Holland, H. D., The Chemucal Evolutzon of the Atmosphere and Oceans, 582 pp., Princeton University Press, Princeton, N. J., 1984.

Hudson, R. D., Absorption cross sections of stratospheric molecules, Can. J. Chem., 52, 1465-1478, 1974.

Hudson, R. D., and S. H. Mahle, Photodissociation rates of molecular oxygen in the mesosphere and lower thermosphere, J. Geophys. Res., 77, 2902-2914, 1972.

Hudson, R. D., and Reed, E. I. (Eds.), The Stratosphere: Present and Future, NASA RP1049, p. 581979.

Hunten, D. M. The escape of $\mathrm{H}_{2}$ from Titan, J. Atmos. Sci., 30, 726-732, 1973a.

Hunten, D. M., The escape of light gases from planetary atmospheres, J. Atmos. Sci., 90, 1481-1494, 1973b.

Hunten, D. M., Thermal and nonthermal escape mechanisms for terrestrial bodies, Planet. Space Sci., SO, 773-783, 1982.

Hunten, D. M., and T. M. Donahue, Hydrogen loss from the terrestrial planets, Annu. Rev. Earth Planet. Sci., 4, 265-292, 1976.

Hunten, D. M., and D. F. Strobel, Production and escape of terrestrial hydrogen, J. Atmos. Scr., 31, 305-317, 1974.

Hunten, D. M., R. O. Pepin, and J. C. G. Walker, Mass fractionation in hydrodynamic escape, Icarus, 69, 532-549, 1987.

Kasting, J. F. The evolution of oxygen and ozone in the Earth's atmosphere, Ph.D. thesis, Univ. of Mich., Ann Arbor, 1979.

Kasting, J. F., and J. B. Pollack, Loss of water from Venus, I, Hydrodynamic escape of hydrogen, Icarus, 58, 479-508, 1983.

Kirby, K., E. R. Constantinides, S. Babeu, M. Oppenheimer, and G. A. Victor, Photoionization and photoabsorption cross sections of $\mathrm{He}, \mathrm{O}, \mathrm{N}_{2}$, and $\mathrm{O}_{2}$ for aeronomic calculations, At. Data Nucl. Data Tables, 23, 63-81, 1979.

Klais, O., P. C. Anderson, and M. J. Kurylo, A reinvestigation of the temperature dependence of the rate constant for the reaction $\mathrm{O}+\mathrm{O}_{2}+\mathrm{M} \rightarrow \mathrm{O}_{3}+\mathrm{M}$ (for $\mathrm{M}=\mathrm{O}_{2}, \mathrm{~N}_{2}$, and $\mathrm{Ar}$ ) by the flash photolysis resonance fluorescence technique, Int. J. Chem. Kinet., 12, 469-490, 1980.

Kley, D., $\mathrm{Ly}(\alpha)$ absorption cross-section of $\mathrm{H}_{2} \mathrm{O}$ and $\mathrm{O}_{2}, J$. Atmos. Chem., 2, 203-210, 1984.
Kockarts, G., Deuterium distributions in the Earth's upper atmosphere, Space Res., XII, 1047-1050, 1972.

Lee, L. C., and M. Suto, Quantitative photoabsorption and fluorescence study of $\mathrm{H}_{2} \mathrm{O}$ and $\mathrm{D}_{2} \mathrm{O}$ at 50-190 nm, Chem. Phys., 110, 161-169, 1986.

Liu, S. C., and T. M. Donahue, The aeronomy of hydrogen in the atmosphere of the Earth, J. Atmos. Sci., 31, 1118-1136, 1974a.

Liu, S. C., and T. M. Donahue, Mesospheric hydrogen related to exospheric escape mechanisms, J. Atmos. Sci., 31, 1466-1470, $1974 \mathrm{~b}$.

Liu, S. C., and T. M. Donahue, Realistic model of hydrogen constituents in the lower atmosphere and escape flux from the upper atmosphere, J. Atmos. Sci., 31, 2238-2242, 1974c.

Maher, L. J., and B. A. Tinsley, Atomic hydrogen escape rate due to charge exchange with hot plasmaspheric ions, $J$. Geophys. Res., 82, 689-695, 1977.

Miller, T. M., and B. Bederson, Atomic and molecular polarizabilities - A review of recent advances, Adv. At. Mol. Phys., 18, $1-55,1977$.

Newman, J. H., J. D. Cogan, D. L. Ziegler, D. E. Nitz, R. D. Rundel, K. A. Smith, and R. F. Stebbings, Charge transfer in $\mathrm{H}^{+}-\mathrm{H}$ and $\mathrm{H}^{+}-\mathrm{D}$ collisions within the energy range $0.1-150$ eV, Phys. Rev., A25, 2976-2984, 1982.

Pollack, J. B., and Y. L. Yung, Origin and evolution of planetary atmospheres, Annu. Rev. Earth Planet. Sci., 8, 425-487, 1980.

Prather, M. J., Ozone in the upper stratosphere and mesosphere, J. Geophys. Res., 86, 5325-5338, 1981.

Ravishankara, A. R., J. M. Nicovich, R. L. Thompson, and F. P. Tully, Kinetic study of the reaction of $\mathrm{OH}$ with $\mathrm{H}_{2}$ and $\mathrm{D}_{2}$ from 250 to $1050 \mathrm{~K}, J$. Phys. Chem., 85, 2498-2503, 1981

Rottman, G. J., Rocket measurements of the solar spectral irradiance during solar minimum, 1972-1977, J. Geophys. Res., 86 6697-6705, 1981.

Schügers, M., and K. H. Welge, Absorptionskoeffizient von $\mathrm{H}_{2} \mathrm{O}_{2}$ und $\mathrm{N}_{2} \mathrm{H}_{4}$ zwischen 1200 and $2000 \AA, Z$. Naturforsch. $A, 23$, 1508-1510, 1968.

Shardanand, and A. D. P. Rao, Collision-induced absorption of $\mathrm{O}_{2}$ in the Herzberg continuum, J. Quant. Spectrosc. Radiat. Thansf., 17, 433-439, 1977.

Slanger, T. G., and G. Black, Photodissociative channels at $1216 \AA$ for $\mathrm{H}_{2} \mathrm{O}, \mathrm{NH}_{3}$ and $\mathrm{CH}_{4}, J$. Chem. Phys., $77,2432-2437$, 1982.

Stief, L. J., W. A. Payne, and R. B. Klemm, A flash photolysisresonance fluorescence study of the formation of $O\left({ }^{1} \mathrm{D}\right)$ in the photolysis of water and the reaction of $\mathrm{O}\left({ }^{1} \mathrm{D}\right)$ with $\mathrm{H}_{2}, \mathrm{Ar}$, and He, J. Geophys. Res., 62, 4000-4008, 1975.

Thompson, B. A., P. Harteck, and R. R. Reeves, Jr., Ultraviolet absorption coefficients of $\mathrm{CO}_{2}, \mathrm{CO}, \mathrm{O}_{2}, \mathrm{H}_{2} \mathrm{O}, \mathrm{N}_{2} \mathrm{O}, \mathrm{NH}_{3}, \mathrm{NO}$ $\mathrm{SO}_{2}$ and $\mathrm{CH}_{4}$ between 1850 and $4000 \AA, J$. Geophys. Res., 68, 6431-6436, 1963.

Tinsley, B. A., The diurnal variation of atomic hydrogen, Planet. Space Sci., 21, 686-691, 1973.

Tinsley, B. A., Hydrogen in the Upper Atmosphere. Fundamentals of Cosmic Physics, vol. 1. pp. 201-300, Gordon and Breach, New York, 1974.

Trainor, D. W., D. O. Ham, and F. Kaufman, Gas phase recombination of hydrogen and deuterium atoms, J. Geophys. Res. 48, 4599-4603, 1973.

Vidal-Madjar, A., J. E. Blamont, and B. Phissamay, Evolution with solar activity of the atomic hydrogen density at 100 kilometers of altitude, J. Geophys. Res., 79, 233-241, 1974.

Walker, J. C. G., Evolution of the Atmopshere, MacMillan, New York, 1977

Watanabe, K., Ultraviolet absorption processes in the upper atmosphere, Adv. Geophys., 5, 153-221, 1958.

Watanabe, K., and M. Zelikoff, Absorption coefficients of water vapor in the vacuum ultraviolet, J. Opt. Soc. Am., 43, 753-755, 1953.

World Meteorological Organization, Atmospheric Ozone, WMO Rep. 16, Geneva, Switzerland, 1985.

Wu, C. Y. R., and D. L. Judge, Lyman- $\alpha$ fluorescence from hydrogen photofragments of $\mathrm{CH}_{4}$ and $\mathrm{H}_{2} \mathrm{O}, J$. Chem. Phys., 75, 172-178, 1981. 
Yung, Y. L., J-S. Wen, J. P. Pinto, M. Allen, K. K. Pierce, and S. Paulson, HDO in the Martian atmosphere: Implications for the abundance of crustal water, Icarus, 76, 146-159, 1988.

Zahnle, K. J., and J. F. Kasting, Mass fractionation during transonic escape and implications for loss of water from Mars and Venus, Icares, 68, 462-480, 1986.

Zahnle, K. J., J. F. Kasting, and J. B. Pollack, Evolution of a steam atmosphere during Earth's accretion, Icarus, 74, 62-97, 1988.

M. Allen, B. M. Landry, J. I. Moses, and Y. L. Yung, Division of Geological and Planetary Sciences, California Institute of Technology, Pasadena, CA 91125.
K. -J. Hsu, Department of Atmospheric Sciences, National Taiwan University, Taipei, Republic of China 10772.

J. -S. Wen, Department of Chemistry, B-017, University of California, San Diego, La Jolla, CA 92093.

(Received June 6, 1988; (revised February 10, 1989; accepted February 10, 1989.) 